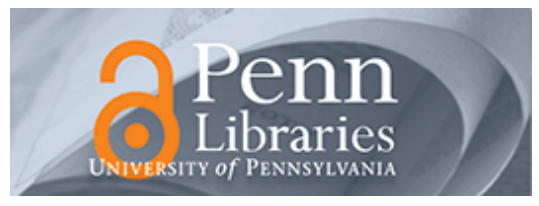

University of Pennsylvania

ScholarlyCommons

Management Papers

Wharton Faculty Research

4-2016

\title{
Innovation Ecosystems and the Pace of Substitution: Re- Examining Technology S-Curves
}

Ron Adner

University of Pennsylvania

Rahul Kapoor

University of Pennsylvania

Follow this and additional works at: https://repository.upenn.edu/mgmt_papers

Part of the Management Sciences and Quantitative Methods Commons

\section{Recommended Citation}

Adner, R., \& Kapoor, R. (2016). Innovation Ecosystems and the Pace of Substitution: Re-Examining Technology S-Curves. Strategic Management Journal, 37 (4), 625-648. http://dx.doi.org/10.1002/ smj.2363

This paper is posted at ScholarlyCommons. https://repository.upenn.edu/mgmt_papers/179

For more information, please contact repository@pobox.upenn.edu. 


\title{
Innovation Ecosystems and the Pace of Substitution: Re-Examining Technology S-Curves
}

\author{
Abstract \\ Why do some new technologies emerge and quickly supplant incumbent technologies while others take \\ years or decades to take off? We explore this question by presenting a framework that considers both the \\ focal competing technologies as well as the ecosystems in which they are embedded. Within our \\ framework, each episode of technology transition is characterized by the ecosystem emergence \\ challenge that confronts the new technology and the ecosystem extension opportunity that is available to \\ the old technology. We identify four qualitatively distinct regimes with clear predictions for the pace of \\ substitution. Evidence from 10 episodes of technology transitions in the semiconductor lithography \\ equipment industry from 1972 to 2009 offers strong support for our framework. We discuss the \\ implication of our approach for firm strategy.

\section{Disciplines} \\ Management Sciences and Quantitative Methods
}




\title{
Innovation Ecosystems and the Pace of Substitution: Re-examining Technology S-curves
}

\author{
Ron Adner \\ Tuck School of Business, Dartmouth College \\ Strategy and Management 100 Tuck Hall \\ Hanover, NH 03755, USA \\ Tel: 16036469185 \\ Email: ron.adner@dartmouth.edu \\ Rahul Kapoor \\ The Wharton School \\ University of Pennsylvania \\ Philadelphia, PA-19104 \\ Tel : 12158986458 \\ Email:kapoorr@wharton.upenn.edu
}

October 10, 2011

\begin{abstract}
Why do some new technologies emerge and immediately supplant incumbent technologies while others take years or decades to takeoff? We explore this question through a framework that weighs the emergence challenges that need to be overcome by a new technology against the extension opportunities that are available to the old technology. We consider both the focal competing technologies as well as the external technology ecosystems in which they are developed and used. We apply this framework to analyze ten episodes of technology competition that have occurred in the semiconductor lithography equipment industry from 1972 to 2009. The framework provides a robust explanation for the observed differences in the pace of substitution. We consider the implication of these findings for both firm strategy and $\mathrm{R} \& \mathrm{D}$ policy.
\end{abstract}

We thank Phil Anderson, Mary Benner, Dan Levinthal, Lori Rosenkopf, Dan Snow, Mary Tripsas, Christophe Van den Bulte, Arvids Ziedonis, Peter Zemsky and seminar participants at HBS, INSEAD, MIT, USC, Wharton, and the 2010 West Coast Research Symposium and the two anonymous reviewers for their helpful comments. We especially thank VLSI Research for their generosity in sharing their data with us and the many industry professionals who provided us with valuable insights. 


\section{INTRODUCTION}

The emergence of a new technology holds the promise, to society, of better things to come, and the threat, to incumbents, of good things coming to an end. With good reason, technology substitution has been a dominant focus of the innovation literature since its beginnings (i.e., Schumpeter, 1942). However, while the waves of creative destruction regularly crash on the shores of markets, the pace of substitution varies markedly across different contexts and different time periods. Some new technological waves wreak havoc on the established technological regimes and dominate their markets in a matter of quarters (e.g., rotary cement kiln in cement production, transistors in mini computers (Tushman and Anderson, 1986), some take years or decades (e.g., 3G telephony, E-books), while others fall upon the shore and recede, leaving but trace remains in a niche (e.g., WAP telephony, Segway).

Although the literature has made significant inroads in characterizing the nature of the threat posed by a new technology and its implications for innovating firms, much less attention has been paid to the dynamics by which new technologies transition from ex-ante threat to ex-post market dominance While great progress has been made in identifying whether a new technology holds the potential to dominate an old technology (e.g., Foster, 1986;, Christensen, 1997), and whether the new technology reinforces or undermines the position of industry incumbents (Abernathy and Clark, 1985; Tushman and Anderson, 1986; Henderson and Clark, 1990; Tripsas, 1997; Hill and Rothaermel, 2003; Lavie, 2006; Benner, 2010), there has been relatively little explicit investigation of how and why the pace of substitution varies across different episodes of technology competition (Henderson, 1995; Ansari and Garud, 2009 are notable exceptions).

This paper presents a structured approach to analyzing the pace of technology substitution that considers the interplay between the emergence challenges that need to be overcome in order for users to benefit from a new technology's superior performance and the extension opportunities that are available to improve the performance of the old technology. We argue that understanding differences in the pace of substitution requires the joint consideration of both emergence challenges and extension opportunities. In assessing emergence challenges and extension opportunities we take a systems view of technology (e.g., 
Rosenberg, 1976, 1982; Hughes, 1983; Henderson and Clark, 1990; Tushman and Rosenkopf, 1992;

Langlois and Robertson, 1995; Garud and Kumaraswamy, 1993; Henderson, 1995; Ethiraj 2007), considering not only developments in the focal technologies that are competing for dominance, but also developments in the technology ecosystem in which each of the focal technologies is embedded (Adner, 2006; Adner and Kapoor, 2010). In so doing we draw a key distinction between the as-developed performance of a focal technology, which depends on the components and the product architecture (e.g., the battery and design of an electric car), and the as-used performance of the technology which depends additionally on the complements which users integrate with the focal technology (e.g. the quality of the charging infrastructure). We develop a framework in which technology competition is assessed according to the balance of emergence challenges for the new technology and extension opportunities for the old technology. We use these two dimensions to identify four qualitatively distinct substitution regimes and predict a clear ordering of the pace of substitution across these regimes. Our approach clarifies how the competing effects of emergence challenges and extension opportunities for the focal technologies as well as their surrounding ecosystems interact to determine when and how technology substitution takes place.

We test the predictions from our framework in the context of the semiconductor lithography equipment industry from 1972 to 2009 , during which ten new technology generations were introduced into the industry. In each case, the market leading technology generation confronted a viable, superior, new technology; the new technology offered higher performance than the old (e.g., Foster, 1986), customers were always well informed about the availability of the new technology (e.g., Rogers, 1995); and customers were eager to adopt higher performance products (e.g., Christensen, 1997). Yet despite these structural similarities, substitution dynamics varied widely across the technology generations, ranging from cases of rapid substitution, to slow substitution, to non- substitution. We apply our framework to explain the variance in substitution dynamics - the difference in the interval between the time a new technology's first commercial sale and the time it achieves dominant industry market share. In so doing we articulate and explore micro-foundations of technology substitution. 
Our approach is closest to Ansari and Garud (2009), who examined the influence of numerous elements within the socio-technical system that shaped the transition between second generation $(2 \mathrm{G})$ and third generation $(3 \mathrm{G})$ mobile communication networks. Their study considers a broader range of factors than does ours, extending beyond the technology focus of the present paper to include the effects of the marketing and messaging strategies, the regulatory environment, and the role of funding sources and the institutional context that underlie the social construction of technologies and markets (e.g., Bijker, Hughes and Pinch, 1987; Geels, 2002). Whereas their study presents conjectures about the direct effects of emergence and extension, we take the interaction between these forces as our central construct and show why it is critical to examine them jointly. We complement their work by developing an explicit framework that considers the degree of emergence challenges and extension opportunities across the new and old technologies, and identifies how and why their interaction can give rise to qualitatively distinct substitution regimes.

We draw on a unique array of primary and secondary data to explicate and test our arguments. We explore a number of additional implications that derive from viewing technology races through the lens of emergence challenges vs. extension opportunities. We explore the ways in which the industry has managed the interaction between new technology emergence and old technology extension to shed light on the puzzling observation that, despite many misses and delays in the commercialization of new lithography technologies, semiconductor manufacturers has continued to make steady progress along the performance trajectory predicted by Moore's law. From a broader technology management perspective, we consider implications for resource allocation across technology generations, firms' entry timing choices, and the use of different coordination mechanisms in the face of technological change. Finally, from a policy perspective, we consider the proactive identification of looming bottlenecks to progress in the core technology that lie in the external ecosystem, and how these might lead to a reevaluation of where to target the allocation of institutional and community resources for industrial support. 


\section{TECHNOLOGY SUBSTITUTION}

Explaining the dynamics of substitution is an important goal of the technology strategy literature. S-curves have become the canonical representations of both the technology life cycle and of competing technologies (i.e., Foster, 1986; Utterback, 1994). The S-curve approach holds that the magnitude of performance improvement in a given technology for a fixed unit of effort or time is relatively low during the early development stages. As the technology is better understood, the rate of progress increases until the stage of maturity, at which point the technology approaches its limits and the performance impact of additional efforts to improve the technology are subject to decreasing returns.

In the context of competing technologies, Foster's influential work posited that the substitution threat becomes salient when the new technology moves beyond its development stage, and that substitution occurs when the new technology's performance surpasses the performance of the old technology - the point at which the new S-curve crosses the old (Foster, 1986). Christensen (1997) observed that substitution can take place even when the new technology is inferior to the old, arguing that if consumers are over-served along the main performance dimension they may switch to the new technology if it offers superior performance on new dimensions. Adner (2002) found that such disruptive dynamics can be explained in terms of price and cost asymmetries. Other studies have shown how new technologies can be incubated in distant markets, emerging as substitute threats when they reach a sufficient performance level (Levinthal, 1998; Adner and Levinthal, 2001) or when triggered by a discontinuous shift in the preferences of consumers in the core market (Tripsas, 2008).

Notice, however, that most studies in this vein implicitly frame substitution as an event that is governed by the rise of the new technology. They pay the bulk of their attention to understanding whether the new technology arises from a market domain that is nearer or farther from the current customer base; whether it draws on knowledge domains that are nearer or further from the current competence base; whether it favors established firms or new entrants. The focus in this literature has been on understanding where, and by whom, the new technology will be incubated before it reaches the mainstream market, with the assumption that once it is available commercially, the new technology will dominate the market. 
Beyond the performance level of the new technology itself, however, two additional factors play an important role in determining the dynamics of substitution: the performance evolution of the old technology after the introduction of the new technology; and the role of ecosystem elements on determining the performance-in-use (as opposed to performance-as-developed) gap between the old and new technologies.

Substitution reflects consumers' choice to stop using the old technology and start using the new. As such, it is important to consider not just the performance trajectory of the new technology, but also that of the old technology. Specifically, although the canonical representation posits a flat-lining of the old technology's performance trajectory, this is not necessarily the case. Indeed, cases of old technology extension have been well documented in settings ranging from sailing ships (Harley, 1971) to pond ice harvesting (Utterback, 1994) to typesetters (Tripsas, 2008) to carburetors (Snow, 2004) to mobile telephony (Ansari and Garud, 2009). Henderson's pioneering (1995) study identified the key role of improvements in components, complements, and users' capabilities in extending the performance trajectory of optical lithography. A key insight in Henderson's study is that predictions regarding an 'old' technology's performance limits must be informed by a holistic assessment of the potential for performance improvements in its surrounding ecosystem.

Fundamentally, what matter for consumers is not the performance of a technology "asdeveloped"; rather, what matters is the performance of the technology "as-used." The as-developed performance of a given technology depends on the interaction between components and the focal architectures into which these components are integrated (Figure 1a). It is this performance-as-developed that has been the focus of much of the literature on technology S-curves. In contrast, the as-used performance of a technology depends not only on the as developed performance of the focal technology, but also on the performance of the complements with which users will combine it to derive their value (Figure 1b).

(Insert Figures $1 \mathrm{a}$ and $1 \mathrm{~b}$ about here) 
Consider the example of electric cars, which are threatening to substitute traditional gas-powered cars on the basis of energy efficiency and emissions reduction. Although this competition is often framed as one between products (i.e., electric vs. gas-powered vehicles) its outcome will be determined by the competition between systems. Here, as-developed product performance is determined by the interaction between the battery components (e.g., how much electric charge can be stored in the battery) and the design of the car (e.g., how efficiently is energy consumed within the car, such as through regenerative braking systems that captures the energy generated from slowing the car and transfers it back to the battery). But once launched, the as-used performance of an electric car depends on complementary elements such as the charging station infrastructure (e.g., how convenient it is for a driver to recharge the battery). Taking such a systems view, it follows that the competition between gas and electric cars should not be assessed on the basis of the standalone product or artifact, but rather be considered within the context of the entire technology ecosystem on which the products' performance depends.

Historical accounts of technology evolution have explicitly shown that underlying a technology's advance are systemic efforts by component and complement providers from a range of industries. For example, Constant's (1980) extensive account of the progress in aircraft piston-engine technology between 1910 and 1945 pointed to the critical role of improvements in the engine components by suppliers such as General Electric, as well as improvements in the complements of fuels and lubricants by oil companies such as Royal Dutch Shell. Such systemic efforts that transcend a given firm or industry are even more prominent today as technologies become more complex and firms get more specialized.

Progress in a given technology can also be hindered by interdependencies in the ecosystem. Rosenberg's (1963) account of the technological change in the American machine tool industry points to numerous episodes of "technological imbalance" in which improvements in machine tool technology could only be realized by users after improvements in other interdependent technologies such as drills and cutting materials were achieved. Similarly, Hughes' (1983) rich description of the evolution of the electrical power system in different market contexts highlights the impact of technological 
interdependencies and performance bottlenecks on adoption. Since substitution is ultimately a question of consumers' changing adoption choices, the true measure of performance must be performance-in-use, and so must include consideration of progress in the critical components and complements that comprise the complete solution that users will compare.

In our analysis of technology substitution we highlight how the performance of ecosystem elements can play two distinct roles. First (as in Henderson, 1995), it can extend the useful life of a focal technology, when improvements in ecosystem elements offset maturity in the focal technology, allowing the focal technology to function beyond its 'stand-alone' potential. Second, and in direct contrast to the first, it can delay the emergence of a new technology when the performance of complements lags that of the focal technology, creating a technology bottleneck that keeps it from functioning at its 'stand-alone' potential. A direct implication of this approach is that any one of these three trajectories can act as a binding constraint on system performance: it is the combined effect of the components, product architecture, and complements that determines the in-use performance of the competing technologies, which is ultimately the driver of technology substitution (Figure 2).

(Insert Figure 2 about here)

\section{The Pace of Technology Substitution: Emergence Challenges vs. Extension Opportunities}

In the context of interdependent technologies, substitution must be viewed not as a race between a new technology and an old technology, but rather as a race between a new technology ecosystem and an old technology ecosystem. As such, two key factors come to the fore. For the new technology, we must consider the dynamics of emergence - the challenges within the ecosystem that need to be resolved in order for the technology to achieve its commercial potential once it is introduced into the market. In the case of electric cars, beyond delivering a car with superior performance-as-developed, it entails the emergence of sufficiently robust complements (charging infrastructure). Beyond emergence, however, substitution requires superiority. In this regard, the new technology's emergence challenges must be 
evaluated against the old technology's extension opportunities - the opportunities available within the ecosystem for further improving the old technology's performance in-use. In the case of gas-powered cars, extension opportunities have included improvements in components such as the internal combustion engine and the fuel pump, as well as in complements such as cleaner burning fuels. ${ }^{1}$ Thus, the pace of substitution is jointly determined by the rate at which the new technology's ecosystem can overcome its emergence challenges relative to the rate at which the old technology's ecosystem can exploit its extension opportunities. $^{2}$ It is the balance of these forces as illustrated in figure 3 that forms the basis of our framework.

\section{(Insert Figure 3 about here)}

Assessing the emergence challenges of a new technology against the extension opportunities for the old technology gives rise to four different substitution regimes. Figure 4 presents our organizing framework for analyzing technology substitution, and provides illustrative examples for each regime.

(Insert Figure 4 about here)

When the emergence challenge for the new technology is low and the extension opportunity for the old technology is low (quadrant 1), the new technology can be expected to achieve market dominance

\footnotetext{
${ }^{1}$ Our goal in this study is to characterize the emergence challenges that arise for the new higher performance technology (as-developed) to achieve a higher performance as-used. For this reason, the technology emergence challenges that are relevant to the new technology concern the challenges with respect to the availability of complements, whereas extension opportunities for the old technology can be rooted in improvements anywhere in the ecosystem.

${ }^{2}$ Garud and Kumaraswamy (1995) discuss the economies of substitution that characterize the extent to which components can be reused when systems are upgraded. Greater economies of substitution, enabled by greater modularity in components, increase the efficiency and effectiveness of new product developments. This reuse of components and complements can occur within a technology generation (thereby serving as a basis of extension opportunity) -- as well as across technology generations (thereby serving as a basis for overcoming development and emergence challenges). As such, economies of substitution can alternately act to prolong the life of the old technology or to speed its demise.
} 
quickly. Its performance-in-use is not held back by bottlenecks elsewhere in the ecosystem, and the old technology's potential to improve in response to the threat is limited. This quadrant is most consistent with the popular imagery of creative destruction and punctuated equilibria. While the old technology can continue serving niches for an extended duration (e.g., Adner and Snow, 2010), the bulk of the market will abandon it in (relatively) short order in favor of the new technology.

Hypothesis 1: The pace of substitution will be fastest when the ecosystem emergence challenge for the new technology is low and the ecosystem extension opportunity for the old technology is low.

When the extension/emergence balance shifts, however, we can expect very different dynamics. In diametric opposition to the prior case, is the case when ecosystem emergence challenge for the new technology is high and the ecosystem extension opportunity for the old technology is high (Quadrant 4). Here, despite the promise of the new technology, its performance-in-use is constrained by progress in the ecosystem. Moreover, the old technology stands to benefit from improvement in its own components and complements that enhance its performance-in-use, even if the performance of the focal technology itself is static. This quadrant is most consistent with technologies that seem revolutionary ex-ante and over hyped ex-post. Here, the old technology can be expected to maintain a prosperous leadership position - secure, high share in a growing market - for an extended period.

Hypothesis 2: The pace of substitution will be slowest when the ecosystem emergence challenge for the new technology is high and the ecosystem extension opportunity for the old technology is high.

Whereas quadrants 1 and 4 offer direct contrasts between fast and slow substitution, the offdiagonal quadrants (2 and 3 ) result in more nuanced dynamics. When the emergence challenge for the new technology is low and the extension opportunity for the old is high (quadrant 2), competition between the old and new technology will be robust. The new technology will make inroads into the market, but 
improvements in the incumbent technology's ecosystem allow it to compete robustly and defend its market share. We expect a prolonged period of coexistence before substitution takes place. Although extension opportunities are unlikely to reverse the rise of the new technology, they will materially delay its dominance and slow the rate of substitution.

Hypothesis 3: The pace of substitution will be intermediate when the ecosystem emergence challenge for the new technology is low and the ecosystem extension opportunity for the old technology is high.

In contrast, when the emergence challenge is high for the new technology and the extension opportunity is low for the old technology (quadrant 3), substitution will be delayed until emergence challenges are resolved, but once they are resolved substitution will be rapid. Here, an analysis of market share will likely show that the old technology maintains high market share, but that market growth has stalled. Because rapid market share inversion is to be expected once the new technology fulfills its performance-in-use potential, dominance by the incumbent is fragile, in the sense that it is maintained not by the incumbent's success, but by the entrant's setback.

Hypothesis 4: The pace of substitution will be punctuated - first very slow then very fast - when the ecosystem emergence challenge for the new technology is high and the ecosystem extension opportunity for the old technology is low.

Thus, Hypotheses 1-3 posit a rank ordering of time-to-substitution while Hypothesis 4 posits a temporal pattern. Note that, beyond technological drivers, emergence challenges and extension opportunities that impact performance-in-use also arise from non-technological factors such as coordination costs and distribution of power among ecosystem participants, the presence or absence of standards and network externalities, industry concentration, institutional, regulatory and societal concerns, 
and the like. Also, as in any study of open systems which are by definition unbounded, a critical choice regards where to draw the boundaries of the analysis (Scott, 1998). In this study we limit our attention to technological drivers and exploit our context as a control for non-technological factors. Among technology drivers we focus on the external elements that link directly to the focal technology -- the components that impact performance-as-developed and the complements that users will combine with the focal technology to determine performance-as-used. Clearly the analysis could be extended to consider higher tiered relationships (e.g., components of components). We consider this framework a baseline structure on which additional technological and non-technological factors can be overlaid. Our hypotheses should be viewed as ceteris paribus predictions regarding the relative pace of substitution.

\section{METHODOLOGY AND DATA}

We examine the interplay of emergence and extension using a detailed history of semiconductor lithography equipment industry from 1972-2009. Lithography is a key process used in semiconductor manufacturing. The rate of technological progress in the semiconductor lithography equipment industry is among the most robust in economic history. Throughout its history, the industry has consistently enabled improvements in the performance of semiconductors by reducing the size of the smallest feature (also called minimum feature size) that can be patterned on the semiconductor. We examine ten cases of technology competition between a dominant old technology generation and a higher performing new technology generation that occurred in the semiconductor lithography industry between 1972 and 2009 . These ten cases account for every instance of competition involving a new commercially launched technology that occurred during this time period.

We test our theory using a research design that employs multiple cases within a single industry (Yin, 1994; Eisenhardt, 1989). We treat each case of technology competition as an experiment that tests a specific relationship between our independent variables - the ecosystem emergence challenge that confronts the new technology and the ecosystem extension opportunity available to the old technology, and our dependent variable - the pace of substitution. This multi-case design allows us to test whether the pattern predicted in the theory matches the outcomes observed in the experiments (Yin, 1994; Lee et. al., 1999). 
The semiconductor lithography industry offers a particularly good context in which to explore the dynamics of substitution. It is a context of robust technological change, as illustrated by the relatively high frequency of technology transitions. Simultaneously, it is characterized by remarkable continuity in terms of consumer preferences, the nature of core competences, the value and importance of complementary assets, as well as by the absence of network externalities. This combination yields sufficient variance in the variables that are of interest to our study, while simultaneously offering a powerful set of natural controls for the key variables that have been identified in the literature, but which are not important drivers of our theory. By drawing all the cases from a single industry we are able to exploit characteristics of the context to create a set of natural controls and to use our acquired knowledge of the context to rule out a number of alternative explanations. This allows us to focus very directly on the effects of our independent variables.

We used both primary and archival data to characterize each of the ten cases of technology substitution and assess their correspondence with our theory. We conducted multiple interviews with 32 industry experts, most of whom have been associated with the industry for more than 20 years. The interviewees came from a variety of positions within the ecosystem: toolmakers, semiconductor manufacturers, suppliers, complementors, industry associations, and consultants. The interviews were semi-structured and lasted two hours on average. Figure 5 shows the distribution of interviewee affiliations. $^{3}$

We used the information from the interviews to develop an understanding of the emergence challenges and extension opportunities within the ecosystems of the different lithography technology generations. Frequently, we followed up with the experts through emails or phone calls in clarifying some of the technical details. In parallel, we read industry literature extensively and, in particular, coded technical developments in the leading industry trade journal - Solid State Technology, and the annual conference proceedings published by the Society of Photo-Optical Instrumentation Engineers (SPIE). We obtained detailed sales data and product specifications for each of the lithography technology generations from VLSI Research, a leading research firm in the industry. For contact and proximity technology

\footnotetext{
${ }^{3}$ The figure lists a total of 42 affiliations because several of our interviewees had multiple affiliations. For example, a number of SEMATECH experts were on long assignment from their semiconductor manufacturer employers.
} 
generations, we supplemented the data from VLSI Research with product specifications reported in the Henderson Photolithography FIVE Data (Henderson, 1993; Helfat and Klepper, 2007).

(Insert Figure 5 about here)

We operationalize the pace of substitution as the time interval between the year of first commercial sale of a new technology generation and the year in which the annual market share of the new technology exceeds the annual market share of the old (previously dominant) technology.

We operationalize the technology ecosystem along the schema illustrated in Figure 1b. The outputs of upstream actors serve as inputs to the focal actor. We refer to such inputs, which are bundled by the focal actor into its product, as components. The focal actor's product serves as an input to the downstream user. A user may also need to bundle other offers alongside the focal actor's product in order to utilize the focal actor's product. We refer to such offers, which are bundled downstream by the user, as complements. Thus, components and complements are defined according to where elements are bundled in the flow of activities relative to the position of the focal product, not according to whether they are produced by a given firm or outsourced to another. In the figure, as in our study, we examine only the key first-tier components and complements that impact performance-as-developed and performance-in-use; clearly, this structure can be extended forward and backward along the activity chain to include higher tiered actors (e.g., supplier's suppliers; customer's customers).

We use this data to construct binary High-Low measures of the extent of emergence challenge and extension opportunity that we use to test our four hypotheses. We describe these measures below when we discuss technological emergence and extension in our context.

\section{SEMICONDUCTOR LITHOGRAPHY TECHNOLOGY}

Semiconductor lithography is the process by which a circuit design is imprinted on a semiconductor substrate called a wafer. The basic principle of lithography is illustrated in Figure 6. After the design of an integrated circuit (IC) is finalized (i.e., the wiring, the gates and the junctions), the circuit blueprint is transferred to a "mask". The lithography process takes place when beams of energy 
originating from an "energy source" are directed onto the mask. The pattern on the mask allows a portion of the energy beams to pass through, with or without an optical "lens" system, onto the wafer. The wafer is coated with an energy sensitive "resist". The resist undergoes a chemical reaction wherever the mask has allowed the energy to pass through. This chemical reaction changes the structure of the resist and allows its selective removal from the wafer. Another chemical process is then initiated in which the exposed parts of the wafer are etched. Finally, the remaining resist is removed, creating a final circuit that replicates the initial design.

\section{(Insert Figure 6 about here)}

The process is carried out using lithography alignment equipment or what is commonly referred to in the industry as the lithography tool. The energy source and the lens are the two key components that are integrated by equipment manufacturers into the lithography tool. A semiconductor manufacturer may use scores of lithography tools in a single production line. With modern tools costing over twenty million dollars each, investments in lithography equipment represent a substantial portion of the cost of a fabrication facility. To maintain competitiveness, semiconductor manufacturers continuously reinvest in their facilities and look to new tool generations to allow them to offer products with higher performance at lower marginal cost. The mask and the resist are the two main complements that semiconductor manufacturers must integrate with the lithography tool to carry out the lithography process. Hence, the lithography technology ecosystem comprises of the lithography tool as the focal technology, the energy source and the lens as key components, and the mask and the resist as the key complements (Figure 7). ${ }^{4}$

(Insert Figure 7 about here)

\footnotetext{
${ }^{4}$ Three of the earliest technology generations transmitted the energy directly from the source to the wafer without using a lens. These were the Contact, Proximity, and X-ray generations.
} 
The main measure of performance in semiconductor lithography is the resolution, the smallest feature size that can be "printed" on the semiconductor wafer and hence, it determines the extent of miniaturization that can be achieved by the semiconductor manufacturer. Smaller feature size allows the semiconductor manufacturers to pack more circuits onto a chip and more chips onto a wafer. For the lithography tool manufacturers this means that improving resolution is a top priority.

The resolution capability of lithography technology is given by the Rayleigh criterion:

$$
\text { Resolution }=k_{1} * \lambda / N A \text {, }
$$

where $\lambda$ is the wavelength of energy being transmitted by the source, NA is a numerical aperture of the lens that is a function of the tool architecture and the size of the lens, and $\mathrm{k}_{1}$ is a process-specific constant that is a function of the mask and the resist complements. Tool manufacturers use three distinct levers to improve the resolution performance of the lithography technology. The first is increasing the size of the lens so as to increase the NA. However, this mode of improvement is limited by the complexity of the lens design and manufacturing, as well as the reduction in the margin of error for the user. ${ }^{5}$ The second is by reducing the wavelength of energy that is transmitted by the source. The final lever includes the modification of the tool architecture so as to alter the path of light waves within the optical system. Although tool manufacturers have played a critical role in the continued progress of the lithography technology, important breakthroughs in the mask and resist technologies have also been made to reduce the value of $\mathrm{k}_{1}$ and extend the performance of the lithography technology.

\footnotetext{
5 The technical term corresponding to the user's margin of error is the depth of focus (DOF). It is the maximum distance between two planes over which there are clear optical images. It can simply be considered as the range of focus errors the lithography process can tolerate and still provide acceptable results. Its relationship to energy wavelength and NA is given by DOF $=k_{2} * \lambda /(\mathrm{NA})^{2}$ where $\mathrm{k}_{2}$ is a constant. An increase in NA, while improving resolution, lowers the DOF and makes the lithography process less robust. As compared to changes in wavelength, the squared NA term has a greater effect on the deterioration in the DOF and hence, limits the tool manufacturers' ability to improve the performance of the lithography technology by increasing the NA (cf. Henderson, 1995).
} 


\section{TECHNOLOGY SUBSTITUTION IN THE SEMICONDUCTOR LITHOGRAPHY INDUSTRY}

The lithography equipment industry distinguishes among generations according to the changes in the tool architecture and in the wavelength of light. From 1972 to 2009, ten distinct generations of lithography equipment have been introduced. ${ }^{6}$ Judged according to the established criteria that have been identified in the technology literature, the conditions of their launches were nearly identical:

At the point of first commercial sale, the resolution performance of each new technology generation was superior to the performance offered by the old technology. This can be seen in Figure 8a, which plots the resolution of each technology generation over its lifecycle. Each of the technology generations were also sustaining (i.e., Christensen, 1997) in that they were developed to meet the needs of firms' existing customers who were demanding improved resolution so as to manufacture integrated circuits (ICs) with higher performance and lower cost. Finally, the composition of the key customer segments, the principle dimensions of performance, as well as the modes through which producers interacted with customers (i.e., Abernathy and Clark, 1985) were all consistent throughout the industry's history; that is, the market was not subjected to substantial shifts in segment composition (Moore, 1991) or to customer preference discontinuities (Tripsas, 2008).

Given these structural similarities, conventional wisdom would yield a prediction that the technology generations should follow similar substitution patterns in which the market quickly transitions out of the old technology and into the new. This, however, is not the case.

Indeed, there is significant variance both in the time it took for the sales of the different generations to take off as well as in the pace of substitution across generations. This is evident in Figure $8 \mathrm{~b}$, which plots the market share of the different technology generations over time. There are cases of fast transitions in which the new technology takes off almost immediately upon its introduction as predicted by

\footnotetext{
6 This definition of lithography generation is consistent with the industry norm as well as Henderson (1988; 1993) and Henderson and Clark (1990). It offers a finer grained level of analysis than the general category of 'optical lithography' used in Henderson (1995), which would group eight of the ten generations examined here (all but Ebeam and X-ray) under the single heading. As discussed below, focusing on the transitions between individual generations offers a more nuanced view of substitution. It also leads us to characterize the failure of X-ray lithography, discussed in Henderson (1995) as driven in large part by its own emergence challenges rather than purely by the successful extension of projection lithography with which it competed at the time of its introduction.
} 
the technology S-curves. These include the projection, G-line and DUV 193-immersion generations. However, there are also cases of slow transitions in which the new technology takes much longer to take off. These include the I-line, DUV 248 and DUV 193 generations. Finally, there were cases of nontransitions in which despite significant development efforts by the industry over many years, the new technology failed to take off. These include the E-beam, X-ray and DUV 157 generations. $^{7}$

(Insert Figure 8a and 8b about here)

We now analyze the correspondence between the differences in the pace of substitution observed in the industry and the emergence-extension characteristics of the ten cases of technology competition. For each case of technology competition, we characterize the extent to which the new technology faced emergence challenges, the extent to which the old technology faced extension opportunities, and the pace of substitution that ensued in each of these transitions. This detailed exercise allows us to illustrate our constructs and contingencies in a much richer way than would a large scale empirical study (Siggelkow, 2007). We use the data to position each case of technology competition in a specific quadrant in our framework and assess the correspondence between the substitution dynamics predicted by our theory and that that was actually observed.

\section{Emergence Challenges in the New Technology Generation}

Each of the new generations presented significant development challenges for the lithography equipment manufacturers. These include challenges in designing the new tool architecture as well as in integrating the different components into the architecture. At the time of first commercial sale, each new generation offered superior performance-as-developed than did the dominant generation. However, these generations differed significantly in the extent to which innovation in complements was required in order

\footnotetext{
${ }^{7}$ Other technology generations such as Ion Beam and Electron Projection were also pursued in the 1970s but did not move beyond R\&D to the commercialization stage and hence are not part of our study.
} 
for the tool generation to achieve its commercialization potential; that is, for its performance-in-use to match its performance-as-developed for the mass market. In the Appendix I, we provide a detailed description of each of the tool generations and the nature of ecosystem emergence challenges for each generation.

In order to provide an objective measure of ecosystem emergence challenge, we counted the number of technical articles published between 1961 and 2010 in Solid State Technology, the leading industry journal, that discuss challenges in the development of Mask and Resist for the new technology generation (see Figure 9). Our industry sources confirmed that a count of published good proxy for the level of technology challenges that surrounded the development of different lithography generations. ${ }^{8}$ The average number of articles across the generations was 4.6. We categorized emergence challenges in those generations that were above this average as 'High' and the other 'Low'. In parallel we surveyed our interviewees about the level of challenges across the different generations. There was uniform agreement among our experts, the documented industry history (i.e., Appendix I), and the article count categorizations.

(Insert Figure 9 about here)

Five of the ten generations faced high emergence challenges, requiring major complement innovations in the mask and resist. These were the E-beam, X-ray, DUV 248, DUV 193 and DUV 157 generations. The emergence challenges in the ecosystem were a result of the reduction in the wavelength

\footnotetext{
${ }^{8}$ We used a number of keywords to identify lithography related articles that were published between 1961 and 2010. The keywords were: lithography, microphotographs, mask, photomask, resist, laser, UV, DUV, Deep UV, optical, lens, stepper, aligner, mercury, illuminator, exposure, printer, and the names of the different generations. We then used the article titles to create a match between the technology generation and whether the article referred to technical problems in mask and resist. If insufficient information was available in the title, we read the abstract and the conclusion to ascertain if the article addressed the innovation challenges in the ecosystem for a given generation. A small subset of articles discussed the mask and resist challenges for multiple generations, and for these articles we read the relevant sections for each generation in order to create a match. Since our primary concern was to assess mask and resist challenges during the emergence of the new technology generation, we excluded articles that were published five years after the generation was commercialized. As a test of robustness, we also used a ten year window and the patterns were fully consistent with our predictions.
} 
of the energy beams that required the development of new materials for the mask and for the resist. The other five generations - Proximity, Projection, G-line, I-line and DUV 193-immersion faced much lower emergence challenges as they were able to reuse the mask and resist technologies that had been developed for the incumbent technology generations i.e., they benefited from cross-generation economies of substitution (Garud and Kumaraswamy, 1995).

However, although the level of emergence challenge is an important differentiator between the generations, it does not fully explain the variance in substitution rates: despite a very low emergence challenge, the I-line generation was slow to replace the predecessor G-line generation. Indeed, if we focus only on emergence challenges without considering extension opportunities we cannot explain findings of robust co-existence (quadrant 2 in figure 4).

\section{Extension Opportunities in the Old Technology Generation}

The different lithography technologies faced very different opportunities for extending their performance in the face of the introduction of the new technology generation. To illustrate the variance in the extension opportunities among the different technology generations we collected the published technical specifications for every lithography tool sold by every major tool manufacturer between 1973 and 2009. Specifically, we collected data on resolution, numerical aperture (NA), wavelength ( $\lambda$ ), and used these to derive the value of $\mathrm{k}_{1}$ for every tool model. To quantify the extension opportunity in every generation that was due to improvements in the ecosystem, we computed the difference in resolution between the best old technology tool sold in the year that the new technology was introduced and the best old technology tool ever sold after that year.

We then used the Raleigh criterion to quantify how much of the old technology's extension opportunity was due to increasing the size of lens (NA), and how much was derived from improvements in 
mask techniques and resist chemistry $\left(\mathrm{k}_{1}\right){ }^{9} \quad$ Figure 10 plots the percentage increase in performance of the old technology from the year the new technology was commercialized that resulted from improvements in $\mathrm{NA}$ and $\mathrm{k} 1$. It shows an unambiguous distinction between generations with low extension opportunities (Contact, Proximity, Projection, DUV 193 following the introduction of DUV 193-immersion) and generations with high extension opportunities (G-line, I-line, DUV 248, DUV 193 following the introduction of DUV 157).

We note that the operationalization of this measure captures the realized extension of the old technology, not the full potential for extension. It assumes that for a given technology generation, a high opportunity for extension corresponds to the observable high realized extension that we measure. That is, there is a possibility that despite high extension potential, we only observe a low extension realization (there is no problem with the case of low potential for extension since it can only result in low realized extension). This is unlikely to be very problematic. In our interviews, industry experts were in unanimous agreement in characterizing the technology bottlenecks that limited extension opportunities. Constant (1980) documented the existence of such predictable technology bottlenecks, which he labeled 'presumptive anomalies,' in aircraft propulsion technology. Moreover, as our interviewees suggested, while there are differences in the incentives and capabilities of individual lithography equipment firms to push the old technology to its limits, there were also differences across customers (semiconductor manufacturers). Specifically, there was always a sub set of customers who preferred to delay the significant switching costs of transitioning their production lines to new lithography technology generations and instead purchase improved versions of old generation tools. . This is consistent with the

\footnotetext{
${ }^{9}$ We note that improvements in $\mathrm{k}_{1}$ were not entirely confined to innovations in mask and resist. Tool makers also contributed to the lowering of $\mathrm{k}_{1}$ by changing the angle of light falling on the mask and hence, enhancing the contrast of the image. This innovation was known as Off-Axis Illumination (OAI). Although its introduction late in the GLine generation was a non-negligible contributor to $\mathrm{k} 1$ improvement, our interviews suggest that its contribution was not as large as that from improvements in resist and mask. Because OAI was incorporated as a standard design element in every subsequent generation launch, it does not affect our measure of extension opportunity for any other generation.
} 
numerous extension efforts observed in other industries ranging from carburetors (Snow, 2004) to sail ships (Hawley, 1971) to pond-ice harvesting (Utterback, 1994).

We are, however sensitive to the fact that this measure does not account for the endogenous choices made by industry participants that ultimately determine how extension potential is realized. After presenting our results, we discuss the different modes through which this realization process has unfolded in the semiconductor lithography industry.

(Insert Figure 10 about here)

Four generations had high extension opportunities. The G-line, I-line, DUV 248, and DUV 193 (at the time of the DUV 157 introduction) generations all benefitted enormously from extension opportunities due to improvements in lens design, lens manufacturing, in combination with new techniques for mask design, for mask manufacturing, and from the introduction and refinements of new resist chemistries.

In six cases of technology competition the old technology had low extension opportunities. The contact and proximity tool architectures did not include a physical lens (i.e., the 'lens' that the energy passed through was air, not glass), so improving NA was not a possible extension mechanism. The projection generation used a reflective lens that made it very difficult to increase NA beyond 0.167 (Henderson, 1995). The extension opportunity for these generations was also limited by the fact that they required the use of masks whose feature size was in a 1-to-1 ratio to the size of the features to be printed on the wafer. This created very high challenges for the mask production process and limited the potential for mask-based extension opportunities. This challenge was greatly relaxed in subsequent generations that were able to use magnification techniques to remove mask resolution as a constraint. By the time DUV 193i was introduced in 2005 the extension opportunities for DUV 193 were severely limited by the physical limits imposed by the lens, mask and resist materials which had already been "stretched" for over two decades. 
However, as was the case for emergence challenge, although the level of extension opportunity is an important differentiator between generations, it too does not fully explain variance in the pace of substitution: despite having low extension opportunity, Projection was not displaced by the E-beam or Xray generations. Indeed, if we focus only on extension opportunities without considering emergence challenges we cannot explain findings of resilience illusion (quadrant 3 in figure 4).

\section{Dynamics of Substitution: Joint consideration of emergence challenges and extension opportunities}

We have characterized each episode of technology competition according to the degree of emergence challenge confronting the new technology and the extension opportunity available to the old technology. We now consider these characterizations jointly to position each case of technology competition in its corresponding quadrant within our framework. Figure 11 matches the transitions to their quadrants and reports the pace of substitution, measured as the number of years between the year the new technology was commercialized and the year it achieved a dominant market share. The observed substitution dynamics in every technology transition supports the hypothesized relationships in each quadrant. ${ }^{10}$

(Insert Figure 11 about here)

\section{Quadrant 1: Creative Destruction}

Four transitions were characterized by low ecosystem emergence challenge for the new technology and low ecosystem extension opportunity for the old technology. Consistent with Hypothesis

\footnotetext{
${ }^{10}$ This figure reports on only the dyadic competition between the new technology and the old dominant technology that it displaced. In many instances, however, the new technology competed with other technologies beyond the dominant incumbent. Appendix II shows an expanded figure that reports on dyadic competition between the new technology and every other technology that was competing for mainstream customers (i.e., every technology that held at least $10 \%$ market share when the new technology was introduced; this boundary precludes comparisons with technologies that were clearly relegated to a niche, such as projection by the time $193 \mathrm{i}$ was introduced). We identify five additional technology rivalries in quadrant 1 , four in quadrant 3 , and one in quadrant 4 . As before, the pace of substitution for generations in quadrant 3 can only be explained if we consider both emergence challenges and extension opportunities.
} 
1, in all these cases the new technology generations (proximity, projection, G-line and DUV 193immersion) achieved very rapid market adoption and were the fastest to substitute the old generation. The average time to substitution in this quadrant is 3 years.

\section{Quadrant 4: Robust Resilience}

Three transitions were characterized by high ecosystem emergence challenge for the new technology and high ecosystem extension opportunity for the old technology. Consistent with Hypothesis 2, these new technology generations (DUV 248, DUV 193 and DUV 157) were the slowest to take off. ${ }^{11}$ A case in point is the transition from I-line to DUV 248. It took DUV 248 eleven years to achieve market dominance. The reduction in the wavelength from I-line's $365 \mathrm{~nm}$ to $248 \mathrm{~nm}$ required significant changes in the key components and complements of the lithography ecosystem. While developing a new mask material was difficult, the most significant emergence challenge in the ecosystem was with the resist. New resist chemistries had to be developed that were sensitive enough to absorb sufficient energy from the lower wavelength to cause the chemical reaction, yet specific enough so as not to react when energy impacted an adjoining molecule. It took several years before a new type of resist chemistry called the chemically amplified resist was developed to meet the commercialization requirements of the DUV 248 technology.

The effect of the resist challenge on the sales growth of DUV 248 generation can be seen in Figure 12. It plots sales of DUV 248 tools and the number of articles appearing in SPIE Proceedings (proceedings of the annual semiconductor lithography industry conference) that discuss resist development for the DUV 248 generation. The resist article measure is a good indicator of the extent of attention that the DUV 248 resist attracted in the R\&D community. The first article appeared in 1984, four years before the first commercial sale of a DUV 248 tool. Attention peaked in 1994, six years after the commercial launch. The sharp decline after this peak is indicative that the major innovation challenges with the resist

\footnotetext{
${ }^{11}$ In fact, the ecosystem emergence challenge for DUV 157 was so significant that, at the time of this writing, it has yet to achieve any meaningful market penetration.
} 
were overcome. What is striking is the correspondence between the decline in article count, which signals the beginning of resolution of major resist-related challenges, and the sales takeoff of the DUV 248 technology.

(Insert Figure 12 about here)

In addition to the ecosystem emergence challenges faced by DUV 248 generation, the transition was further slowed by high extension opportunities for the I-line generation. This extension was achieved through an innovation in the mask called the Phase-Shift technique. The technique allowed for a reduction in the resolution of the lithography technology by lowering the $\mathrm{k}_{1}$ and extending the I-line generation from its initial resolution limit of 500nm to 350nm (Terasawa et al., 1989; NTRS, 1994). This extension raised the performance threshold that the DUV 248 generation needed to cross in order to achieve successful commercialization. The average time to substitution in this quadrant was in excess of 11 years.

\section{Quadrant 2: Robust Coexistence}

The transition from G-line to I-line was characterized by low ecosystem emergence challenge and high ecosystem extension opportunity. It took I-line 7 years to dominate G-line. The intermediate pace of substitution in this quadrant is consistent with the prediction in Hypothesis 3 that the substitution dynamics within this quadrant would entail a robust competition between the old and the new technology until the old technology reaches its limits. This result in a substitution regime that is slower than in quadrant 1 but faster than in quadrant 4 .

Figure 13 shows changes in the ratio of wavelength to Numerical Aperture (NA) for the highest performance G-line and I-line tools sold in a given year. Recall that for a given generation (fixed wavelength), improvement in resolution is achieved by increasing the NA, which is a function of the size of the lens. Figure 13 shows that, after the I-line generation was introduced, there was a corresponding burst in the performance of the G-line generation. This improvement was a result of an increase in NA, 
and continued for six years. It was only when the G-line generation could no longer be extended that the Iline generation gained significant market share. This case illustrates that low emergence challenge is not a sufficient condition for fast substitution. The pace of substitution critically depends on the extension opportunity for the old technology. This point is also reinforced in Figure 14 which shows the contrast in the patterns of substitution that we observe for Quadrants 1 and 2.

(Insert Figures 13 and 14 about here)

\section{Quadrant 3: Resilience Illusion}

Finally, the competition between Projection to E-beam in 1976 and to X-ray in 1978 was characterized by high ecosystem emergence challenge and low ecosystem extension opportunity (lower left quadrant). We predicted in Hypothesis 4 that, in this regime, the old technology, despite having limited extension opportunity, would continue its market dominance until the emergence challenge with the new technology is resolved. However, once the new technology ecosystem has overcome the emergence challenge, the new technology is expected to have a very steep sales takeoff. Hence, during this regime, the old technology's dominance is fragile because its market position is based not in its own strength, but in the rival technology's weakness.

In the case of the Projection vs. E-beam and Projection vs. X-ray competitions, the emergence challenges for E-beam and X-ray were both extremely high. Their shorter wavelengths required dramatic innovation in resist (much the same type of challenge as faced by DUV248 over a decade later) and in the mask (for X-ray). And in the absence of suitable amplified resist and mask complements, neither generation could translate its performance-as-developed advantage into a performance-in-use advantage. ${ }^{12}$ Consistent with the first part of the hypothesis, Projection dominated the market in the early years that followed the introduction of the new technologies. However, neither E-beam nor X-ray replaced

\footnotetext{
${ }^{12}$ We note that while E-beam generation faced high ecosystem emergence challenge, it also suffered from lower throughput that made it less attractive for large scale mass production. We discuss this aspect of E-beam in detail in Appendix I.
} 
Projection in later years. In this regard, the predicted punctuation was not observed. This was due to the fact that the competition became a multi technology race. Specifically, the X-ray generation was commercialized two years after E-beam, and then the G-line generation (which had low emergence challenge) was commercialized before either E-beam or the X-ray's emergence challenge had been overcome. As such, before they had had a chance to displace Projection, both technologies were themselves displaced. The technology competition for dominance rapidly shifted from the mode of old vs. new technology (Projection vs. E-beam) to old vs. newer technology (Projection vs. X-ray) to old vs. newest technology (Projection vs. G-line). Although E-beam and X-ray never displaced Projection, the ‘illusion’ of Projection's resilience is demonstrated by how quickly Projection was displaced by G-line. In this regard, we do observe a punctuated dynamic, but among an altered set of technology rivals.

Thus, by jointly considering new technology's emergence challenge and old technology's extension opportunity we are able to account for the observed differences in the pace of substitution for every case of technology competition in the semiconductor lithography industry.

\section{Alternative Explanations}

Several alternative mechanisms may explain our observed differences in the pace with which the new technology substitutes the old technology in the semiconductor lithography equipment industry. We now consider two key alternative explanations based on the demand environment that have been the focus of prior literature and show why they are unlikely to affect the interpretation of our findings.

\section{Changes in the Demand Structure}

If the proportion of buyers that benefit from the higher performance offered by new technology generation has changed over time, it would certainly affect the pace of substitution (Griliches, 1957; Mansfield, 1968). The semiconductor manufacturers that benefit most from lithography resolution improvements are firms that manufacture microprocessors and Dynamic Random Access Memory (DRAM) chips. These firms are the leading-edge adopters in the semiconductor manufacturing market. 
Figure 15 plots the annual capital expenditures by the leading-edge firms as the proportion of total expenditure by semiconductor manufacturers from 1980-2007 as reported by VLSI Research. It shows that the leading-edge firms are the biggest spenders in the industry so as to continuously upgrade their manufacturing facilities. This trend has been remarkably consistent from 1981 to 1998 in which the leading-edge segment has represented between $60 \%$ and $75 \%$ of the total semiconductor capital expenditures. Hence, the slow adoption of the I-line and the DUV 248 cannot be attributed to changes in the demand environment. In recent years, with the emergence of semiconductor foundries, the relative share of the leading-edge segment has declined somewhat, but they still represent the largest market segment for semiconductor equipment (which is consistent with the fast dominance growth achieved by the latest DUV 193 immersion generation). Thus, there were no major shifts in the structure of demand that might explain our results.

(Insert Figure 15 about here)

\section{Changes in User Capabilities and Preferences}

Another alternative explanation for slower pace of substitution might be the extent to which these technologies undermined user's existing capabilities (Rogers, 1995). However, because the basic science and technological principles have been retained across all lithography generations, such that they have been competence enhancing from a user perspective, there is no reason to believe that a lack of user capabilities explains variance in the pace of substitution. In addition, as compared to the disk drive (Christensen, 1997), typesetter (Tripsas, 2008) and mobile communication (Ansari and Garud, 2009) technologies, in which user preferences for different performance attributes have shifted over time, the preference for improved resolution among the leading-edge users that drive the demand for the new technology generations have been highly consistent throughout the industry's history. In Appendix III, we present results of hedonic regression of lithography tool price and resolution for the different technology 
generations. Consistent with our understanding of user preferences, the coefficient of resolution is highly significant and explains $88 \%$ of variance in tool prices.

This constant presence of the set of natural controls throughout the entire time frame that we study serves to increase our confidence in our results.

\section{POTENTIAL VS. REALIZATION: DIFFERENT FACES OF EXTENSION}

The level of old technology extension is determined jointly by technological possibilities and by the motivations, choices, and actions of industry participants. In studying the patterns of technological change in the semiconductor lithography industry we were able to identify three different modes by which industry participants acted to make potential extension opportunities a reality.

First, in some cases, the extension of the old technology was a "last gasp" effort by individual incumbent firms to prolong the life of their old technology investments. We observed such an extension pattern in the case of the G-line generation after the emergence of the I-line generation. Nikon was the first firm to commercialize the I-line generation in 1985. However, another incumbent firm, Canon, instead chose to focus its R\&D efforts on extending the G-line generation through an increase in the size of the lens, introducing I-line tools only when further extending the performance of the G-line generation was deemed unfeasible. This last gasp effort to reinvigorate performance improvement in mature technologies is of the sort that has been observed in other technologies such as sailing ships (Harley, 1971), pond ice harvesting (Utterback, 1994), typesetters (Tripsas, 2008). The main driver here is differences in innovation incentives among focal firms.

Second, there were instances in which solutions to resolving the technology development challenges in the new technology generation helped in extending the old technology generation. For example, one of the key challenges in the development of DUV 157 generation was the development of new lens materials with high concentration of Calcium Fluoride that would allow for low wavelength light to pass through. The R\&D efforts to resolve this challenge also helped to make better lenses for the incumbent DUV 193 generation and thus contributed to extending its performance. Similarly, the resist 
development for lower wavelength generations helped in improving the chemical composition of the resist used with the older generations. Snow (2004) documents such a "spill back" effect in the automotive industry where the development of the new electronic fuel injection technology created a positive spillover in the old carburetor technology and extended its performance.

Finally, there were instances where extension opportunities were created as a result of collective resource re-allocation by firms in the lithography ecosystem. Over the past forty years, Gordon Moore's (1965) conjecture about the rate of progress in semiconductor manufacturing has taken on the status of a socially constructed 'Law' that has served as a critical coordination mechanism for the industry.

During episodes when industry leaders - industry associations such as SEMATECH and major leading edge semiconductor manufacturers - concluded that the high emergence challenge confronting a new lithography technology generation will making it unlikely that it would be available to allow continued progress according to Moore's law, firms in the lithography ecosystem reallocated their R\&D resources towards extending the old technology generation (e.g. Schellenberg, 2004).

Since the 1990s, progress in semiconductor manufacturing has been coordinated according to collectively defined technology roadmaps, most recently under the auspices of International Technology Roadmap of Semiconductors (ITRS). The roadmap is regarded as a very good indicator of the R\&D resource allocation across the different technology generations. When it was evident that the emergence of DUV 193 in 1996 would be significantly delayed due to the challenges in the resist, which would mean that the generation would not be able to achieve its planned introduction at $180 \mathrm{~nm}$ resolution, the semiconductor industry revised its collective development emphasis. The 1991 roadmap, in expectation that the DUV 193 generation would launch in 1996 with a resolution of $250 \mathrm{~nm}$, specified that the performance of DUV 248 would be limited to 250nm and that this limit would be reached by 1996 (Micro Tech 2000, 1991). As emergence challenges continued to delay the launch of the DUV 193 generation, the 1997 and 1999 roadmaps revised the expected performance limit of DUV 248 to $150 \mathrm{~nm}$ by 1999 and 130nm by 2001 respectively. These revisions signaled a collective agreement to reallocate substantial development resources to extend the performance of DUV 248 (and so away from the DUV 193 effort) as 
a last resort for sustaining the trajectory guided by Moore's law. As a result of these investments, the DUV 248 generation did indeed achieve the resolution performance of 130nm in 2001.

Instead of extension as a last gasp for survival, this third type of extension episode is better characterized as a "last resort." While last gasps are driven by focal firms competing to maximize the value that they can capture from the old technology, these last resort efforts were driven by stakeholders in the broader ecosystem whose prime motivation was to sustain progress along the trajectory specified by Moore's Law for the semiconductor manufacturers. Although an in-depth discussion of the institutional structures that impact the semiconductor industry is beyond the scope of this paper, interested readers are referred to Moore, 1996, Macher et al.,(1999) and Brown and Linden (2009).

Each of the three modes of old technology extension is impacted in a different way by the interaction of the old and new technologies. In the case of last gasps, the old technology's extension arises from increased efforts in response to new competition. In the case of spillbacks, extension arises as a byproduct of progress in the development of the new threat itself. Conversely, In the case of last resorts, extension arises due to a failure of progress in the new technology. Collectively they show that the realization of extension opportunities incorporates a rich set of interactions that go well beyond the identification of technological constraints.

\section{DISCUSSION AND CONCLUSION}

This study sheds light on the forces that determine the pace of technology substitution by presenting a framework for that identifies when and how technology competition is resolved. It considers the relative balance between the emergence challenges confronting the new technology and the extension opportunities available to the old technology as a key governor of these dynamics. Underlying this approach is a view that, in order to understand progress in a given technology, we need to take into account progress in the surrounding ecosystem in which the focal technology is embedded. We apply this framework to study ten episodes of technology competition that have occurred in the semiconductor lithography equipment industry from 1972 to 2009 . We find that the observed dynamics are fully 
consistent with our predictions. Thus, the framework helps to clarify the puzzling variance in transition paths observed in the industry despite the existence of structural similarities across the different cases of technology competition.

In addition to these core findings, our in depth study of the semiconductor lithography industry also sheds light on the different sources of extension in matured technologies. We found that at times, extension was a "last gasp" effort by firms to maximize the value that they can capture from the old technology as they face the threat of imminent substitution. In other instances, we found that extension of the old technology was also a result of the discovery of solutions to the emergence challenges in the new technology. Hence, this form of extension was driven by a technical spillover from the new to the old technology. Finally, we found that extension of the old technology could be spurred by the failure of the new technology to emerge on time. Here, extension was a "last resort" effort by stakeholders in the ecosystem to sustain the progress trajectory of the industry.

Approaching substitution as an outcome of the interplay between extension of the old technology and emergence of the new helps clarify observations that highly discontinuous changes at one level of a technology hierarchy can be invisible at other levels (e.g., Funk, 2008a,b). In the context of semiconductors, we observe that despite many misses and delays in the commercialization of new lithography technologies, semiconductor manufacturers continued to make steady progress along the Moore's law. Whenever semiconductor manufacturers were confronted with the prospect that their lithography tool suppliers would be unable to meet the industry roadmap requirements, they proactively guided resources to finding ways of bridging the gap with the old technology until a new technology solution became available. This 'last resort' reallocation of efforts had great impact on the returns to tool makers' efforts in both the old and new generations.

By focusing on the notion of 'performance-in-use' as driving substitution, rather than simply performance as developed, we are able to draw a link between two of the most fundamental life-cycle patterns identified in the innovation community: the S-curve profiles of technology improvement and the S-curve profile of technology adoption. While the primary use of the technology S-curve has been to 
understand technologies' performance limits, the primary use of the adoption S-curve has been to understand the market potential and timing for a given technology so as to inform a firm's technology and market development strategies (e.g., Fisher and Pry, 1971; Agarwal and Bayus, 2002; Bass, 2004). Studies of adoption patterns (e.g., Griliches, 1957; Rogers, 1995) focus on the dynamics of the demand environment, but most often assume that technology is static. Conversely, studies of technology evolution, focus almost exclusively on the relative performance position of the new and established technologies, and tend to assume that a technology with superior performance will automatically take over a given market. In doing so, they have tended to overlook the role of demand-side adoption in determining the pace and extent of technology substitution (Adner, 2004). Our paper informs and clarifies the relationship between these two fundamental constructs. Specifically, we note that adoption and substitution are intimately linked - a user's decision to adopt the new technology is, implicitly, a decision not to adopt the incumbent technology. Hence, what looks like adoption from the new technology's perspective looks like substitution from the old technology's perspective. They are two sides of the same coin. For this reason, understanding the adoption of a new technology requires not only a detailed demand side analysis of consumer heterogeneity and information diffusion mechanism (e.g., Rogers, 1995) but also consideration of the supply side factors that govern the technological progress within an ecosystem. As with substitution, the pace of adoption will be a function of the dynamics of emergence of the new technology ecosystem and the dynamics of extension of the incumbent technology ecosystem. For example, the emergence of a new technology may require major improvements in the complements for the average user to derive the full benefits, and this may slow the adoption rate. Similarly, the extension of a new technology through improvements in components, architectures or complements may also slow the adoption of the new technology. Such an ecosystem framework is able to explain why new superior technologies may face slow market adoption and why seemingly geriatric technologies may continue to dominate.

In this regard, our approach has some predictive implications. Historically, S-curve analysis has focused on the performance profile of a stand-alone technology. One problem with the S-curve is that the 
time to performance take -off is notoriously difficult to specify ex-ante. Focusing on performance-in-use expands the analysis beyond the time to take-off for the single focal technology, to include the performance profile of the entire ecosystem on which the focal technology's value creation depends. Counter intuitively, this expansion of the consideration set, as depicted in Figure 2, can improve our ability to make predictions. In an interdependent system, performance in-use cannot take off until every element is ready. For this reason, the most challenged element acts as a bottleneck for the whole system. This has an important implication: the take-off of the focal technology's performance as-developed profile will predict performance-in-use takeoff only if the focal technology is the bottleneck of the system. If the focal technology is not the bottleneck, overcoming its development challenge will not affect the system's emergence challenge. For example, much attention has been paid to predicting when hydrogen powered fuel cell technology will be ready to overcome its development challenge, with the implication that once this challenge is overcome, fuel cells will become important technology rivals to gasoline engines (e.g., Ellis et.al., 2001; Ehsani et. al., 2009). Taking a systems view, however, makes it clear that fuel cells will not pose a real substitution threat until they are complemented by a sufficiently developed hydrogen infrastructure. Even casual consideration of the physical, logistic, and regulatory challenges to the development of this critical complement makes it clear that its deployment will be measured in decades, not years. As such, we can be sure that, whether the automotive fuel cell requires four years or eight years to emerge, it will not pose a substitute threat for many years after (i.e., it will fall in quadrant 3 or 4 ). Thus, while we cannot predict when the fuel cell ecosystem will finally emerge, we can be more confident about when it will not emerge - not because fuel cells won't be ready, but because the complementary hydrogen infrastructure will not be. To be clear - we are not suggesting that this approach will offer an accurate prediction of the pace of substitution; rather, we are suggesting that it can offer a more accurate prediction than an approach that does not explicitly consider the interplay between ecosystem extension and emergence. Further, we do believe that there is value in presenting these arguments in the form of a clear framework in which to assess their impact rather than presenting them as standalone variables to be added to the long list of factors to consider. 
This study has a number of implications for firms. First, we propose that rather than viewing technology substitution as the race between focal technologies, firms view them as the race between technology ecosystems. Such a view would help clarify when the new technology will substitute the old technology. Hence, it can inform the way in which firms choose to allocate their valuable R\&D resources according to the likely benefits from being early with the new technology (e.g., Adner and Kapoor, 2010). Second, the explicit consideration of technological interdependencies and asymmetries in the rate of advance among the different ecosystem elements can help firms consider various modes of coordination ranging from vertical integration to collaborative networks. Finally, our framework can help firms in their resource allocation choices between technology development initiatives and development of complementary assets such as production, distribution and brand. For example, when emergence challenge for the new technology is high and the opportunity for extending the old technology is low, firms may be better off allocating a greater proportion of resources towards development of complementary assets rather than in the development of old and new technologies (e.g., Rothaermel and Hill, 2005; Jacobides et al., 2006)

Finally, our study provides some useful insights for policy. While we suggest that the rate of technology substitution will depend on the relative difference in the emergence challenges and extension opportunities that confront the new and old technologies, we note that three of the four types of substitution regimes are characterized by significant technical progress fueled either by the old or the new technology. However, when emergence challenges are high and extension opportunities are low, industries may face stagnation. In quadrant 3, policy makers may have to create additional incentives and mechanisms through which the emergence challenges with the new technology can be overcome in a timely manner. In addition, a robust technology policy may also consider alternative new technologies that may be more likely to overcome emergence challenges.

We view this study as a helpful guide, rather than as a final word. Our empirical analysis has a number of limitations that suggest promising avenues for further work. We test our ideas in the context of a single industry, and expect that other market environments will reveal additional nuances. In particular, 
we expect that the ways in which stakeholders negotiate the modes of extension and emergence will be impacted by the industrial organization of the different market players that need to collaborate in value creation. Moreover, although we do not study them explicitly in this paper, it is clear that the institutional and social contexts in which technologies compete and evolve play critical roles in shaping the timing and nature of outcomes. In this regard, while we view the magnitude of the technology challenges we discuss as relatively exogenous, the resolution of these challenges is highly endogenous, depending on the efforts, investments, urgency, perceptions, and alternatives that are available to the different participants. We expect exploration of these dynamics to be particularly fruitful and hope to pursue it in future work. 


\section{REFERENCES}

Abernathy, W. J., \& Clark, K. B. 1985. Innovation: Mapping the Winds of Creative Destruction. Research Policy 14: 3-22.

Adner, R. 2002. When Are Technologies Disruptive: A Demand-Based View of the Emergence of Competition. Strategic Management Journal 23: 667-688.

Adner, Ron. 2004. "A demand-based perspective on technology life cycles." Business Strategy Over the Industry Lifecycle: Advances in Strategic Management. J. Baum and A. McGahan, eds. 21: 25-43.

Adner, R. 2006. Match your Innovation Strategy to your Innovation Ecosystem. Harvard Business Review 84 (4): 98

Adner, R., \& Levinthal, D. A. 2001. The emergence of emerging technologies. California Management Review 45(1): 50-66.

Adner, R., Kapoor, R. 2010. Value creation in innovation ecosystems: how the structure of technological interdependence affects firm performance in new technology generations. Strategic Management Journal 30(3): 306-333.

Agarwal, R. and Bayus, B. 2002. The Market Evolution and Sales Takeoff of Product Innovations. Management Science 48(8): 1024-1041.

Ansari, S., R. Garud. 2009. Inter-generational transitions in socio-technical systems: The case of mobile communications. Research Policy 38(2): 382-392.

Bass, F. M. 2004. Comments on "A New Product Growth for Model Consumer Durables The Bass Model." Management Science 50(12S):1833-1840.

Benner, Mary J. 2007. The incumbent discount: Stock market categories and response to radical technological change. Academy of Management Review 32: 703-720.

Bijker, W., Hughes, T., Pinch, T. (Eds.), 1987. The social construction of technological systems: New directions in the sociology and history of technology. MIT Press, Cambridge, MA.

Brown, C. and Linden, G.. 2009. Chips and Change: How Crisis Reshapes the Semiconductor Industry. Cambridge, MA: MIT Press.

Christensen, C. M. 1992. Exploring the Limits of the Technology S-Curve. Part I: Component Technologies. Production and Operations Management 1(4): 334-357.

Christensen, C. M. 1997. Innovator's Dilemma: When New Technologies Cause Great Firms to Fail. Boston: Harvard Business School Press.

Constant, E.W. 1980. The Origins of the Turbojet Revolution. Baltimore: Johns Hopkins University Press.

Dosi, G. 1982. Technological Paradigms and Technological Trajectories. Research Policy 11: 147-162.

Ehsani, M., Gao, Y. and Emadi, A. 2009. Modern Electric, Hybrid Electric, and Fuel Cell Vehicles: Fundamentals, Theory, and Design, Second Edition. CRC Press. Boca Raton: Florida.

Ellis, M.W., Von Spakovky, M.R. and Nelson, D.J. 2001. "Fuel cell systems: Efficient, flexible energy conversion for the 21st century." Proceedings of the IEEE 89(12): 1808-1818.

Eisenhardt, E. 1989. Building Theories from Case Study Research. Academy of Management Review 14(4): $532-550$

Ethiraj, S. K. (2007). Allocation of inventive effort in complex product systems, Strategic Management Journal 28 (6), 563-84.

Fisher, J., \& Pry, R. 1972. A simple substitution model of technological change. Technological forecasting and social change 3: 75-88.

Foster, R. 1986. Innovation: The Attacker's Advantage. New York: Summit Books. 
Funk, J. 2008a. Systems, Components and Technological Discontinuities: The Case of the Semiconductor Industry, Industry \& Innovation 15:4,411 - 433

Funk, J. 2008b. Components, Systems, and Technological Discontinuities: Lessons from the IT Sector, Long Range Planning 41(5): 555-573.

Garud, R. and Kumaraswamy, A. 1993. Changing competitive dynamics in network industries: An exploration of Sun Microsystem's open systems strategy. Strategic Management Journal 14(5):351369.

Garud, R. and Kumaraswamy, A. 1995. Technological and organizational designs for realizing economies of substitution. Strategic Management Journal 16:93-109.

Geels, F.W., 2002. Technological transitions as evolutionary reconfiguration processes: a multi-level perspective and a case-study. Research Policy 31 (8-9), 1257-1274.

Griliches, Z. 1957. Hybrid Corn: An Exploration in the Economics of Technological Change . Econometrica 25(4): 501-522

Harley, Charles K. 1971. The shift from sailing ships to steamships, 1850-1890: A study in technological change and its diffusion. In Essays on a mature economy: Britain after 1840, ed. Deirdre N. McCloskey, xv, 439. Princeton, N.J., Princeton University Press.

Helfat, Constance E. and Klepper, Steven. 2007. Firm and Industry Evolution and Entrepreneurship (FIVE Project): Data Overview (November 2, 2007). 2007 Kauffman Symposium on Entrepreneurship and Innovation Data. Available at SSRN: http://ssrn.com/abstract=1022116

Henderson, R. M., \& Clark, K. B. 1990. Architectural innovation: The Reconfiguration of Existing Product Technologies and the Failure of Established Firms. Administrative Science Quarterly, 35(1): 9-30.

Henderson, R. M. 1995. Of Life Cycles Real and Imaginary: The Unexpectedly Long Old Age of Optical Lithography. Research Policy 24(4): 631-643.

Hill CWL, Rothaermel FT. 2003. The performance of incumbent firms in the face of radical technological innovation. Academy of Management Review 28:257-274.

Hughes, T. P. 1983. Networks of Power: Electrification in Western Society 1880 - 1930. Baltimore: Johns Hopkins University Press.

Jacobides, M. G., Knudsen, T., \& Augier, M. 2006. Benefiting from innovation: Value creation, value appropriation and the role of industry architectures. Research Policy 35(8): 1200-1221.

Kapoor, R. and Adner, R. 2007. Technology Interdependence and the Evolution of Semiconductor Lithography. Solid State Technology 50(11): 51-54.

Lavie, D. 2006. Capability reconfiguration: An analysis of incumbent responses to technological change. Academy of Management Review, 31: 153-174

Lee, T. L., Mitchell, T. R., \& Sablynski, C. J. 1999. Qualitative research in organizational and vocational psychology: 1979-1999. Journal of Vocational Behavior 55: 161-187.

Levinthal, D. A. 1998. The slow pace of rapid technological change: gradualism and punctuation in technological change. Industrial and Corporate Change 7(2): 217-247.

Macher, J.T., Mowery, D.C., Hodges, D.A., 1999. Semiconductors. In: Mowery, D. (Ed.), U.S. Industry in 2000: Studies in Competitive Performance. National Academy Press, Washington, DC, pp. 245-286.

Mansfield, E. 1968. Industrial Research and Technological Innovation: An Econometric Analysis. New York: W.W. Norton \& Company.

Mitchell, W. 1989. Whether and When? Probability and Timing of Incumbents' Entry into Emerging Industrial Subfields. Administrative Science Quarterly 34: 208-230.

Moore, G.A. 1992. Crossing the Chasm, Marketing and Selling High-Tech Products to Mainstream Customers.HarperCollins Publishers, New York. 
Moore, G.E., 1996. Some personal perspectives on research in the semiconductor industry. In:

Rosenbloom, R.S., Spencer, W.J. (Eds.), Engines of Innovation. Harvard Business School Press, Boston, pp. 165-174.

Rogers, E. M. 1995. Diffusion of Innovations. New York: The Free Press.

Rosenberg, N. 1963. Technological change in the machine tool industry, 1840-1910. Journal of Economic History, 23(4): 414-443.

Rosenberg, N. 1976. Perspectives on Technology. Cambridge: Cambridge University Press.

Rothaermel FT, Hill CWL. 2005. Technological discontinuities and complementary assets: a longitudinal study of industry and firm performance. Organization Science 16: 52-70.

Sahal, D. 1981. Patterns of Technological Innovation. Addison-Wesley, Reading, MA.

Schellenberg, F.M. 2004. Resolution enhancement technology: the past, the present, and extensions for the future Optical Microlithography XVII. SPIE, Santa Clara, CA, USA, 1-20.

Schilling, M.A. 2008. Strategic management of technological innovation, Second ed. McGraw-Hill/Irwin.

Schumpeter, J. A. 1942. Capitalism, Socialism and Democracy. London: Unwin University Books.

Siggelkow, N. 2007. Persuasion with case studies. Academy of Management Journal 50: 20-24

Snow, D. 2004. Extraordinary Efficiency Growth in Response to New Technology Entries: The Carburetor's Last Gasp. HBS Working Paper.

Sood, A., \& Tellis, G. J. 2005. Technological evolution and radical innovation. Journal of Marketing, 69(3): 152-168.

Terasawa, T., Hasegawa, N. Kurosaki,Tanaka,T.1989. 0.3-micron optical lithography using a phaseshifting mask, Proceedings of the International Society for Optical Engineering 1088: 25-33.

Tripsas, M. 1997. Unraveling the Process of Creative Destruction: Complementary Assets and Incumbent Survival in the Typesetter Industry. Strategic Management Journal 18(6): 119-142.

Tripsas, M. 2008. Customer preference discontinuities: a trigger for radical technological change. Managerial and Decision Economics 29(2-3): 79-97.

Tushman, M. L., \& Anderson, P. 1986. Technological Discontinuities and Organizational Environments. Administrative Science Quarterly 31(3): 439-465.

Tushman M, Rosenkopf L. 1992. Organizational determinants of technological change: Towards a Sociology of Technological Evolution. Research in Organizational Behavior 14: 311-347.

Utterback, J.M. 1994. Mastering the dynamics of innovation: how companies can seize opportunities in the face of technological change. Harvard Business School Press Boston, MA, USA.

Yin, R.K. 1994. Case Study Research: Design and Methods, 3rd ed. Sage, Thousand Oaks, CA. 
Figure 1a: Determinants of Performance As-Developed.

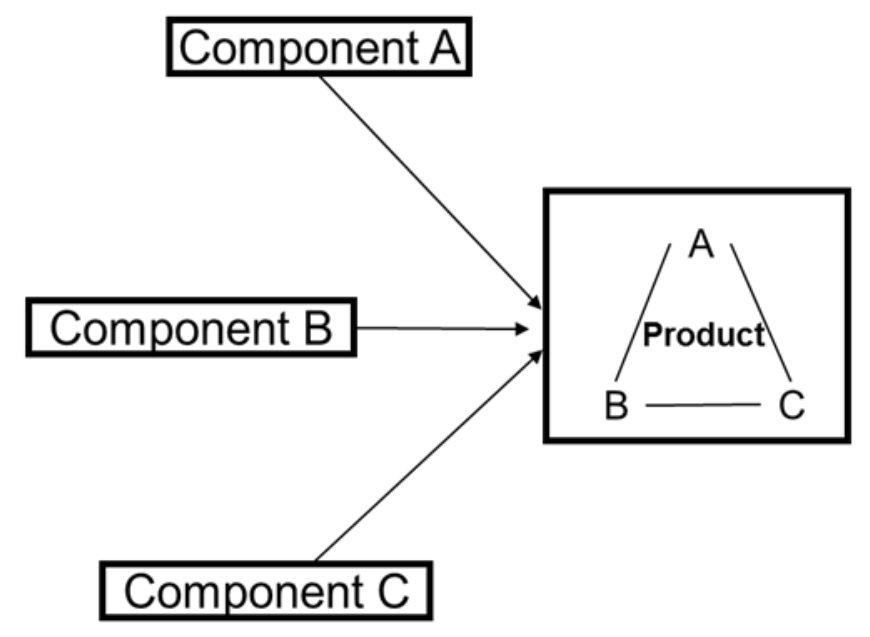

Figure 1b: Determinants of Performance As-Used.

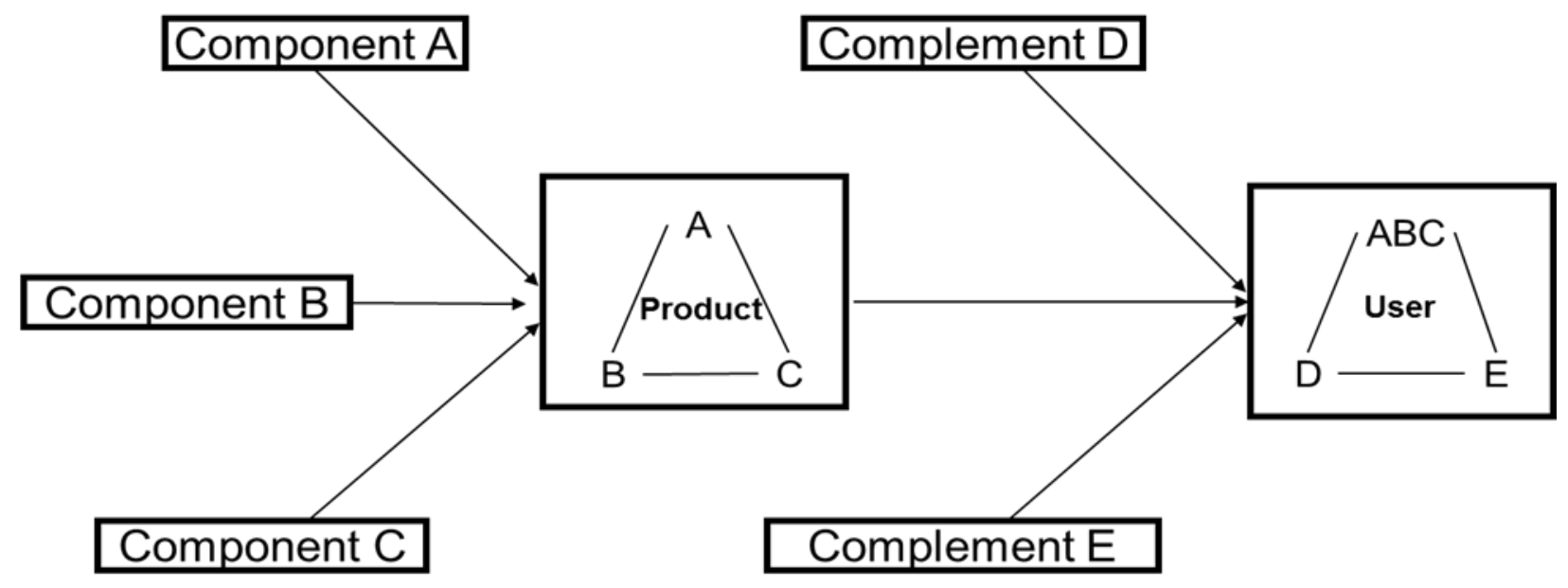


Figure 2: Progress along the technology S-curve as an aggregation of the progress of ecosystem elements.

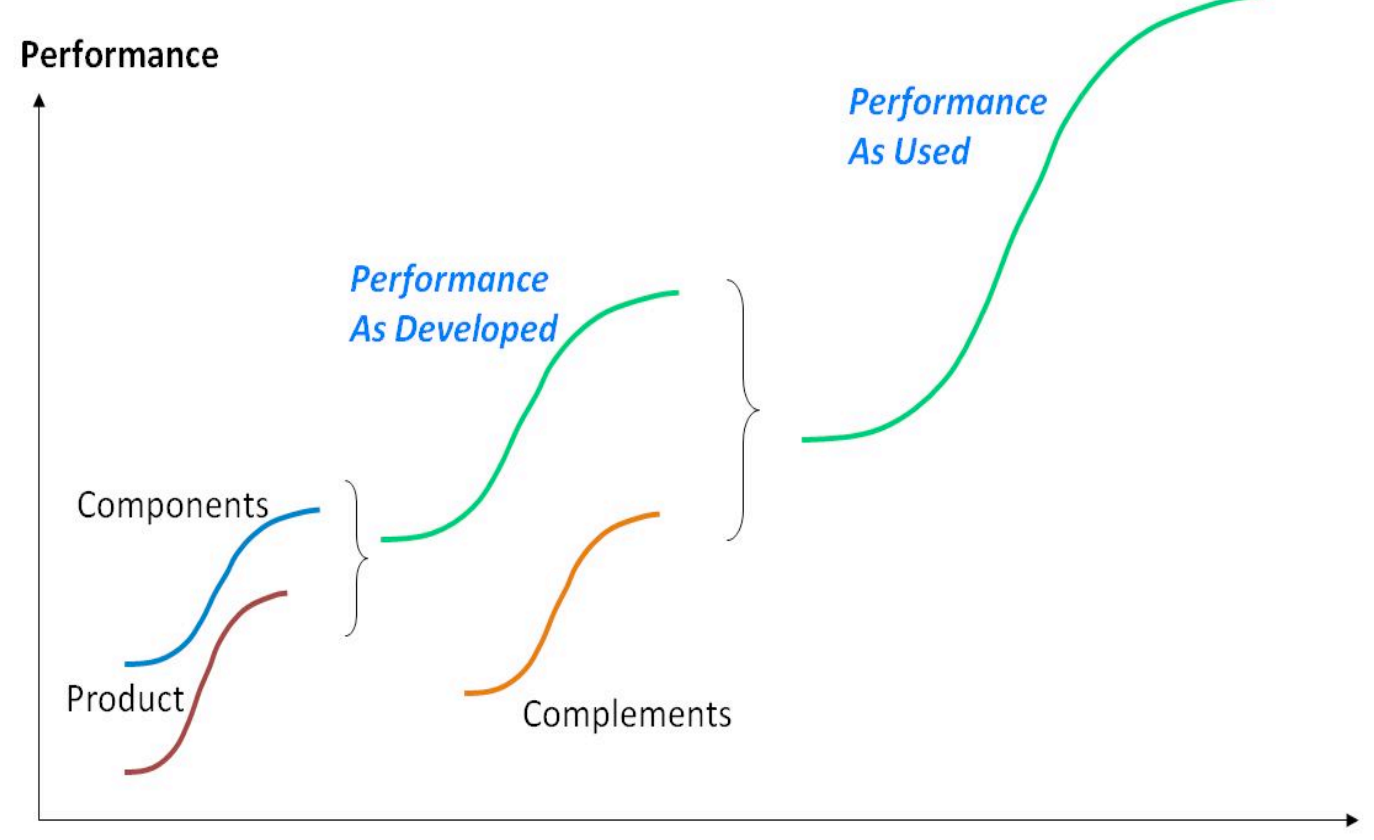

Figure 3: Substitution as a race between old technology extension and new technology emergence.

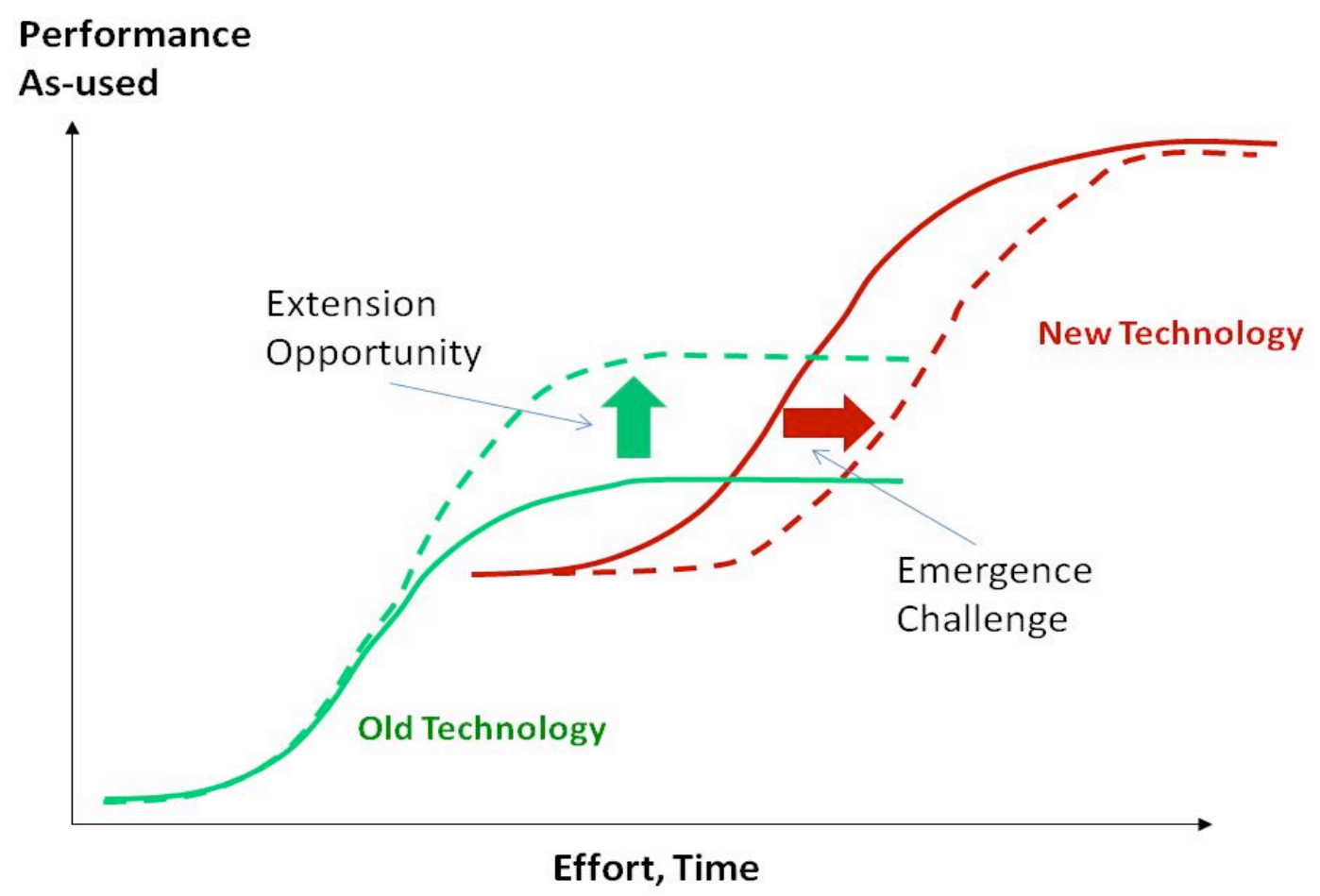


Figure 4: A framework for analyzing technology substitution.

Ecosystem Extension Opportunity (Old Technology)

Low

High

\begin{tabular}{|c|c|c|}
\hline Low & $\begin{array}{l}\text { Quadrant 1: Creative Destruction } \\
\text { Inkjet vs. Dot Matrix Printers } \\
\text { 64MB DRAM vs. 256MB DRAM } \\
\text { Memory Chips }\end{array}$ & $\begin{array}{l}\text { Quadrant 2: Robust Coexistence } \\
\text { Internal Combustion Engines vs. } \\
\text { Hybrid Engines } \\
\text { Magnetic Storage (e.g., Disk } \\
\text { Drives) vs. Solid State Storage } \\
\text { (e.g., Flash Memory) }\end{array}$ \\
\hline High & $\begin{array}{l}\text { Quadrant 3: Resilience Illusion } \\
\text { Paper Maps vs. GPS Based } \\
\text { Navigation Devices } \\
\text { Standard Definition vs. High } \\
\text { Definition Television Broadcast }\end{array}$ & $\begin{array}{l}\text { Quadrant 4: Robust Resilience } \\
\text { Gasoline Fueled Cars vs. Fully } \\
\text { Electric Cars } \\
\text { RFID vs. Bar Codes }\end{array}$ \\
\hline
\end{tabular}

\section{Figure 5: Interviewee Affiliations.}

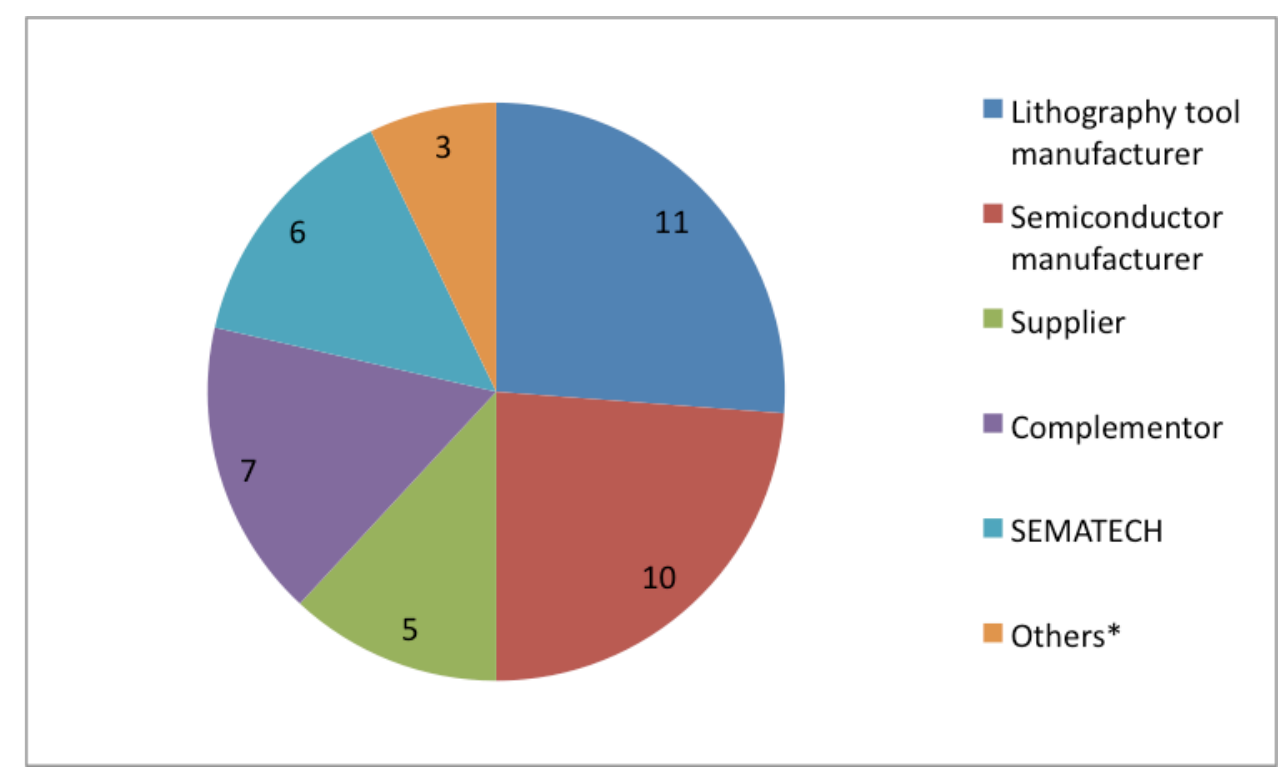


Figure 6: Basic schema of the semiconductor lithography process.

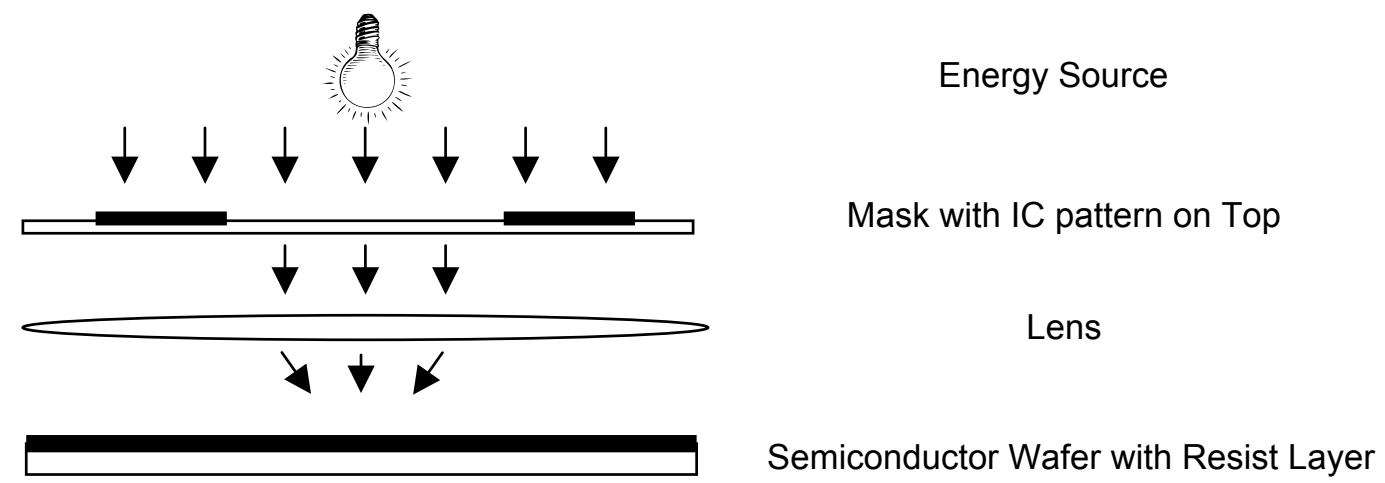

Figure 7: Semiconductor lithography ecosystem.

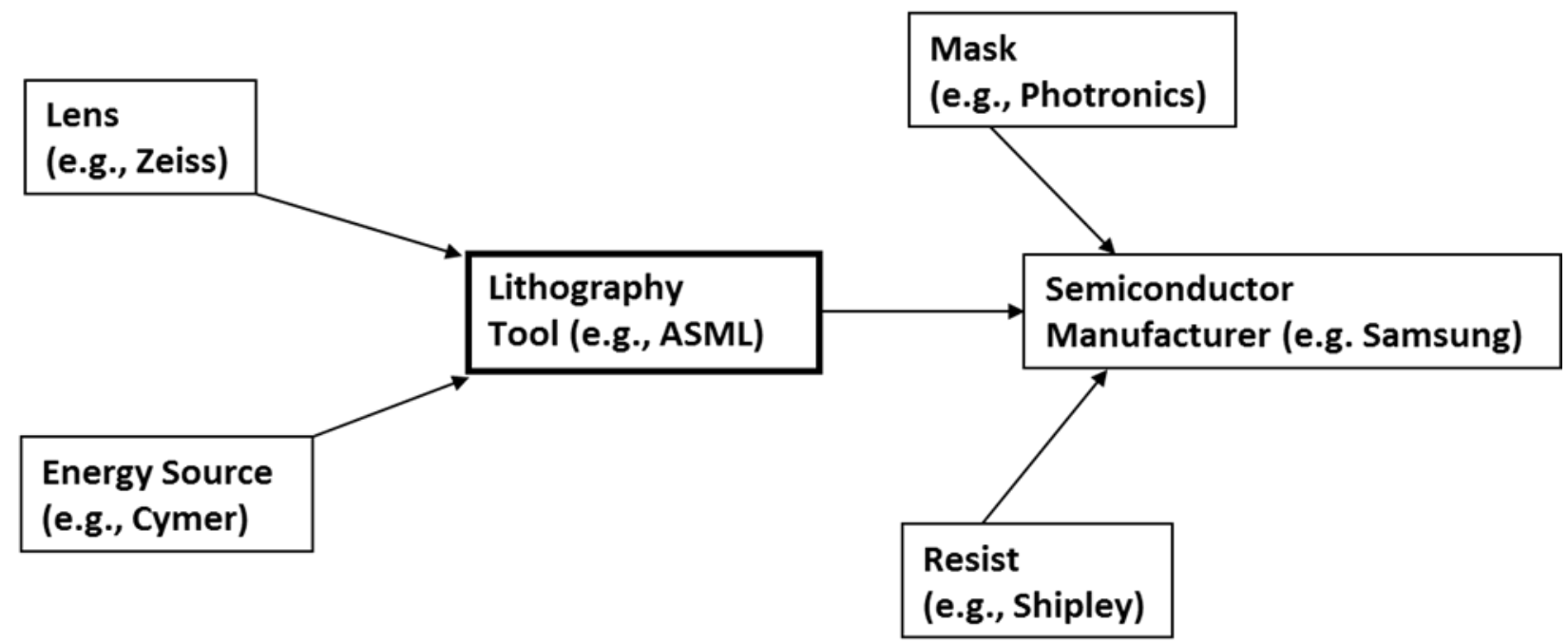


Figure 8a: Resolution capability of the different lithography tool generations.

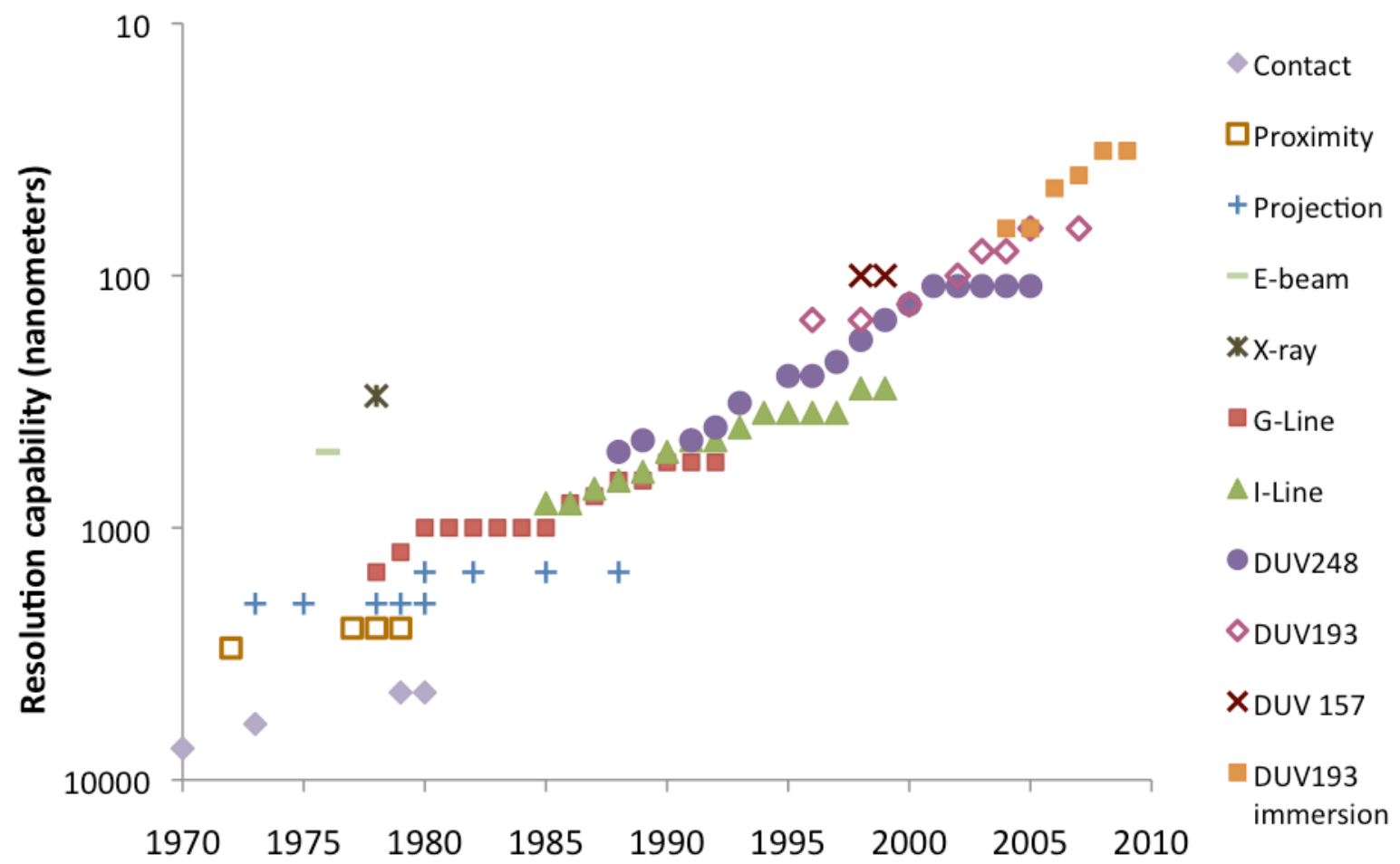

Figure 8b: Market share of the different lithography tool generations.

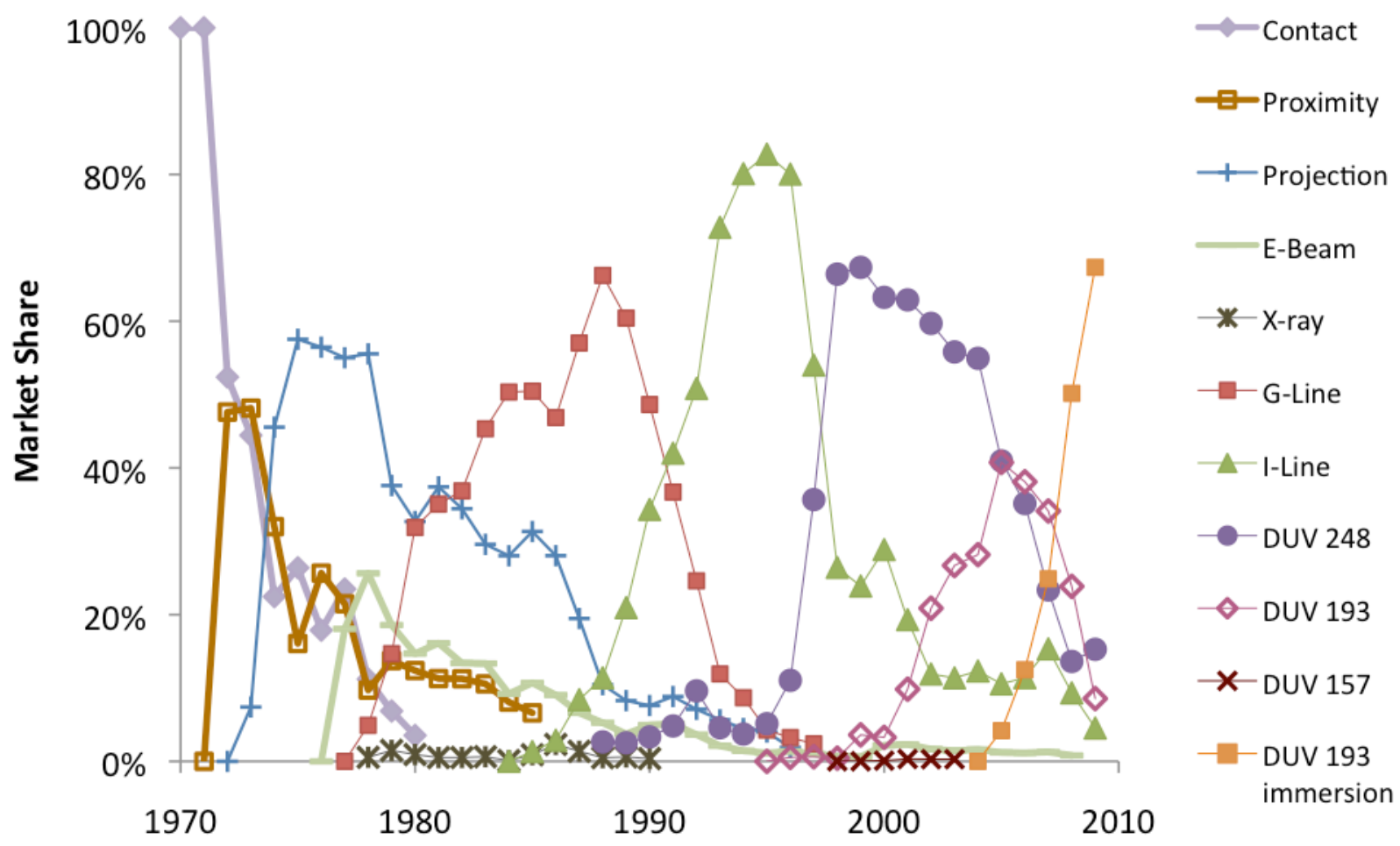


Figure 9: Magnitude of ecosystem emergence challenge for the different technology generations as measured by Solid State Technology article count.

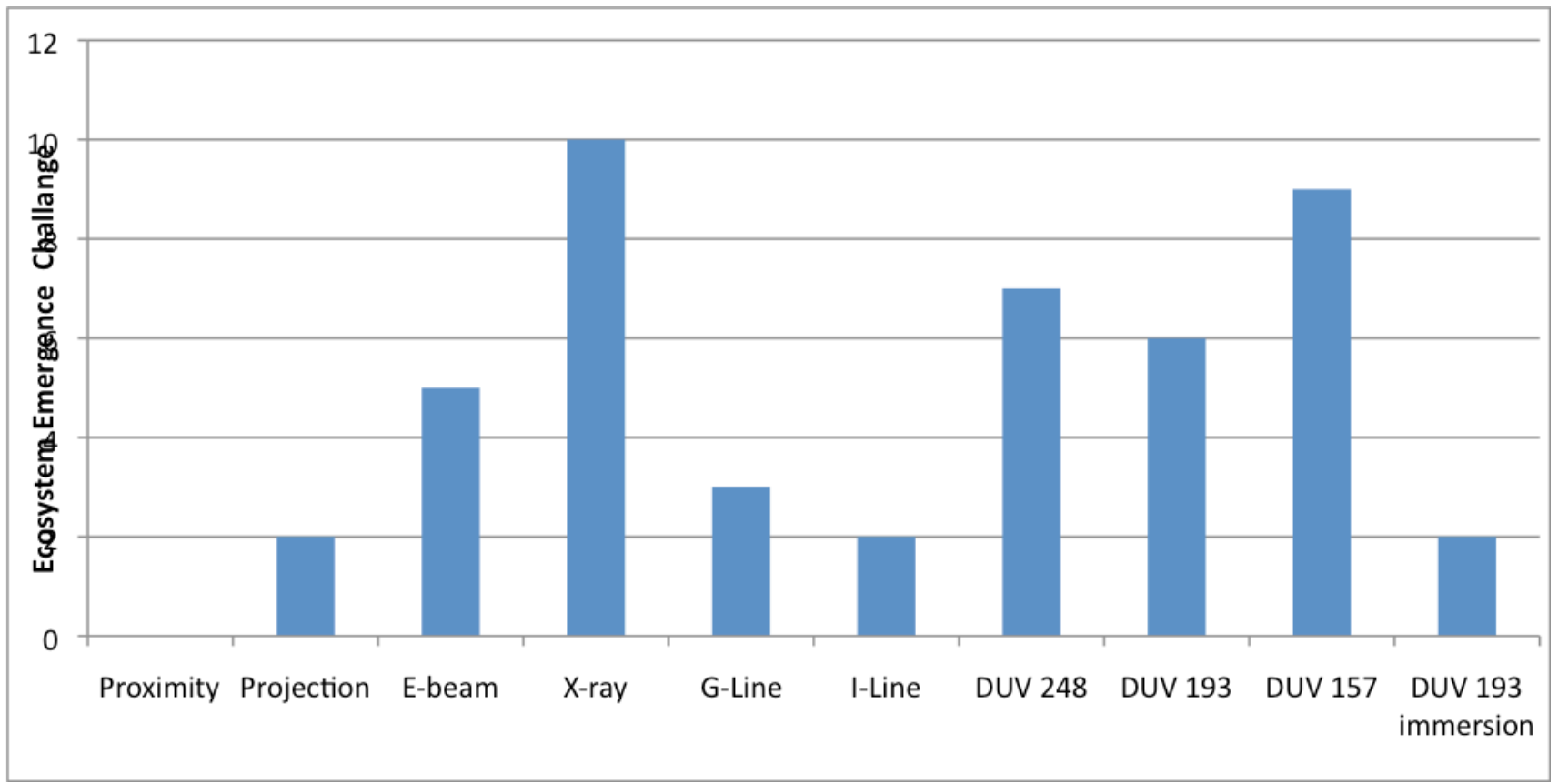

Figure 10: Magnitude of Ecosystem Extension Opportunity for the Different Lithography Technology Generations.

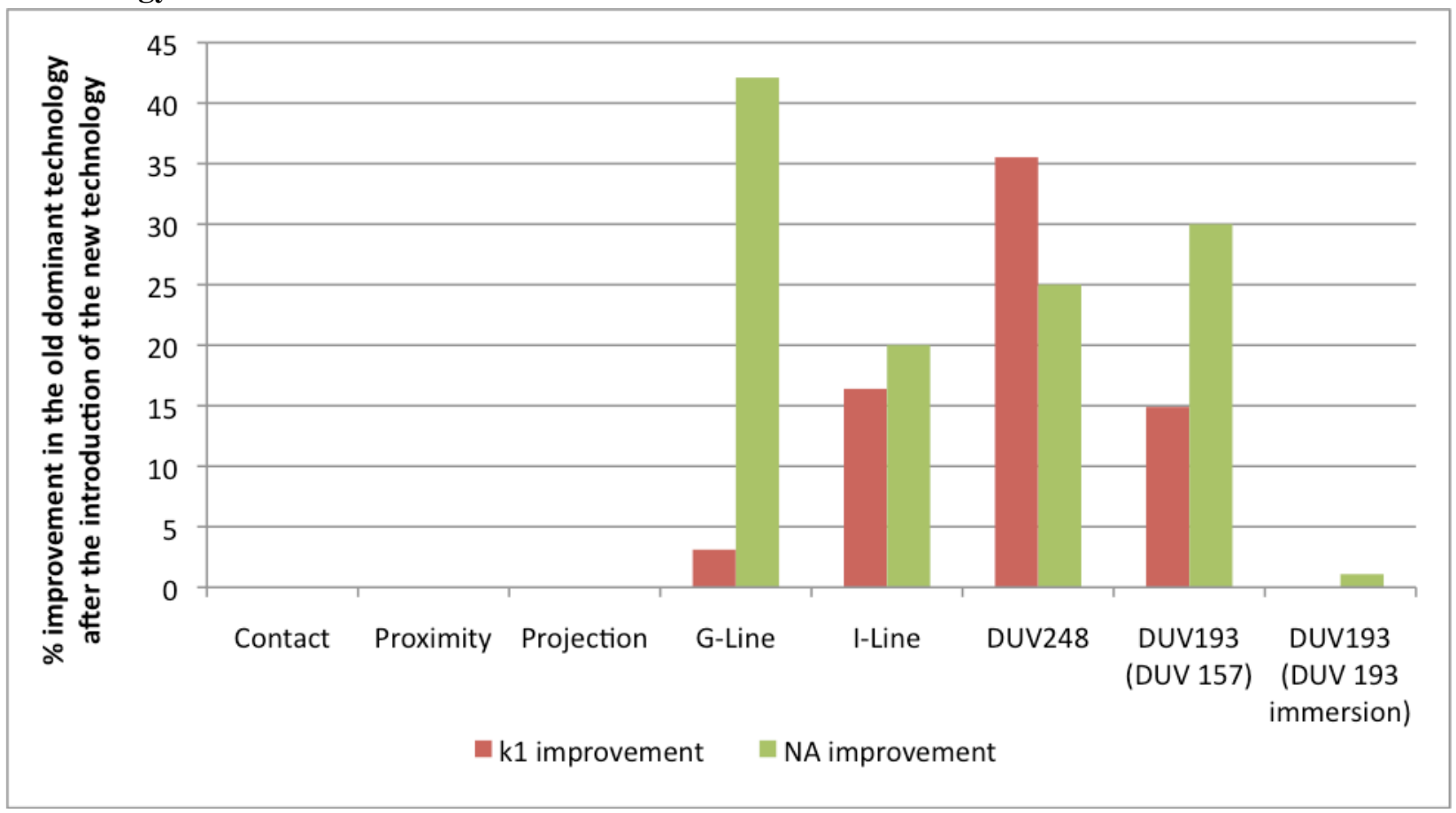


Figure 11: Pace of substitution in the semiconductor lithography industry organized within our framework according to the extension opportunity for the old dominant technology and the emergence challenge for the new technology. Years to market dominance for the new technology are in parentheses. ${ }^{\mathrm{a}}$

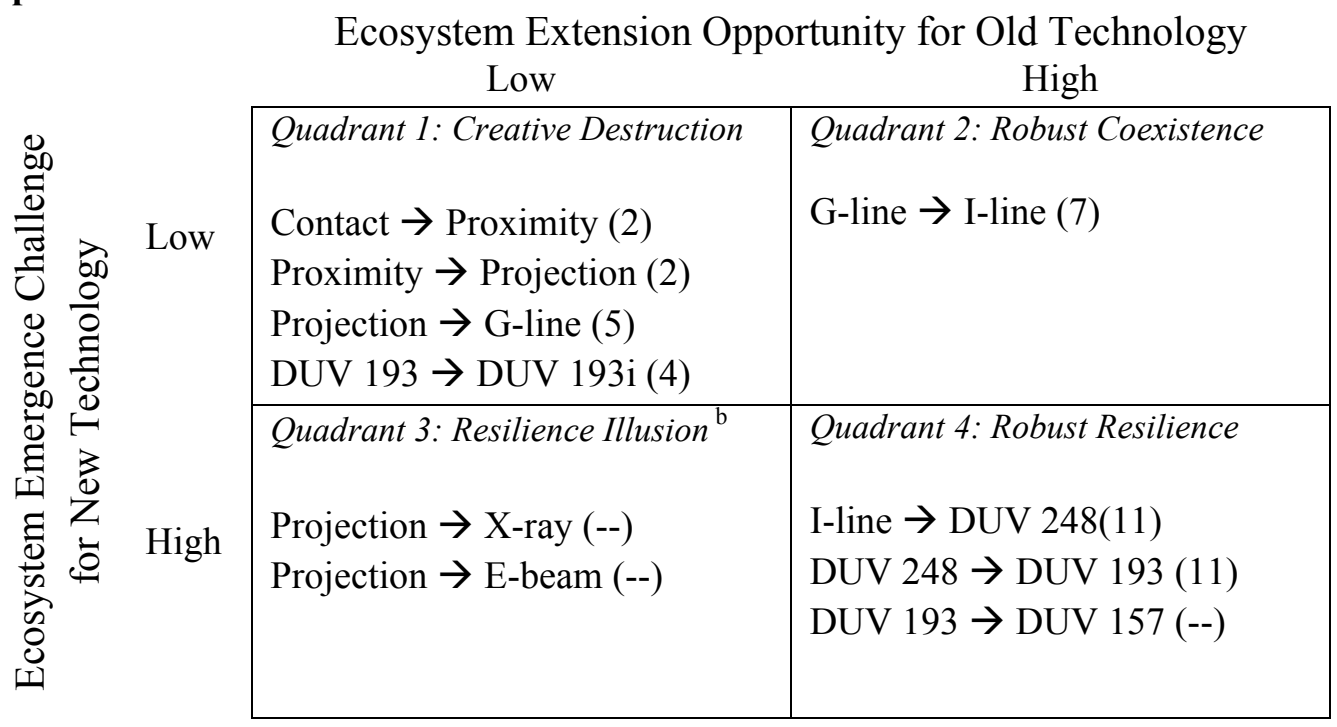

${ }^{a}$ Market dominance is defined as the first year in which the new technology exceeds the annual market share of the old (previously dominant) technology. In competitions marked as (--) the new technology did not achieve dominance over the old technology. Competitive pairs are the Old Dominant Technology $\rightarrow$ New Technology.

${ }^{\mathrm{b}}$ The introduction of E-beam was followed by X-ray which was itself followed by the introduction of G-line and hence, the technology competition rapidly shifted from the mode of old vs. new technology to old vs. newer technology. Although neither E-beam nor X-ray ever displaced Projection (indeed the emergence challenges with both were so great that neither has been able to take off for the last three decades), the 'illusion' of Projection's resilience was demonstrated by how quickly Projection was displaced by G-line.

Figure 12: Trends in the resolution of resist challenge and tool sales for the DUV 248 generation. ${ }^{\mathrm{a}}$

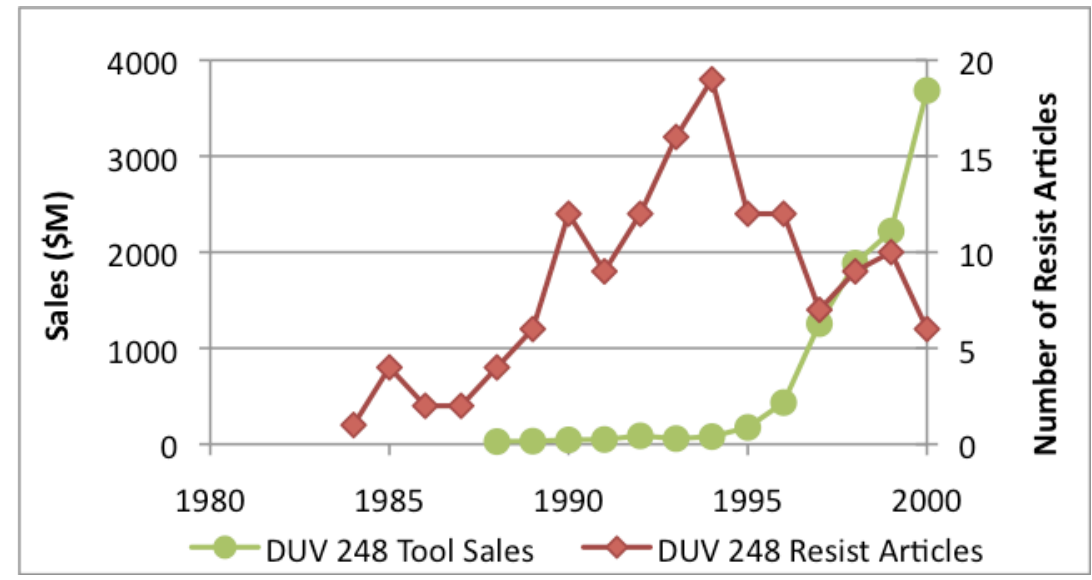

${ }^{a}$ We used the annual number of technical articles on resist development for DUV 248 generation as a proxy for the R\&D efforts being expended to resolve the resist challenge. These articles were published in the annual lithography industry conference. 
Figure 13: Robust coexistence between old (G-line) and new (I-line) technology*

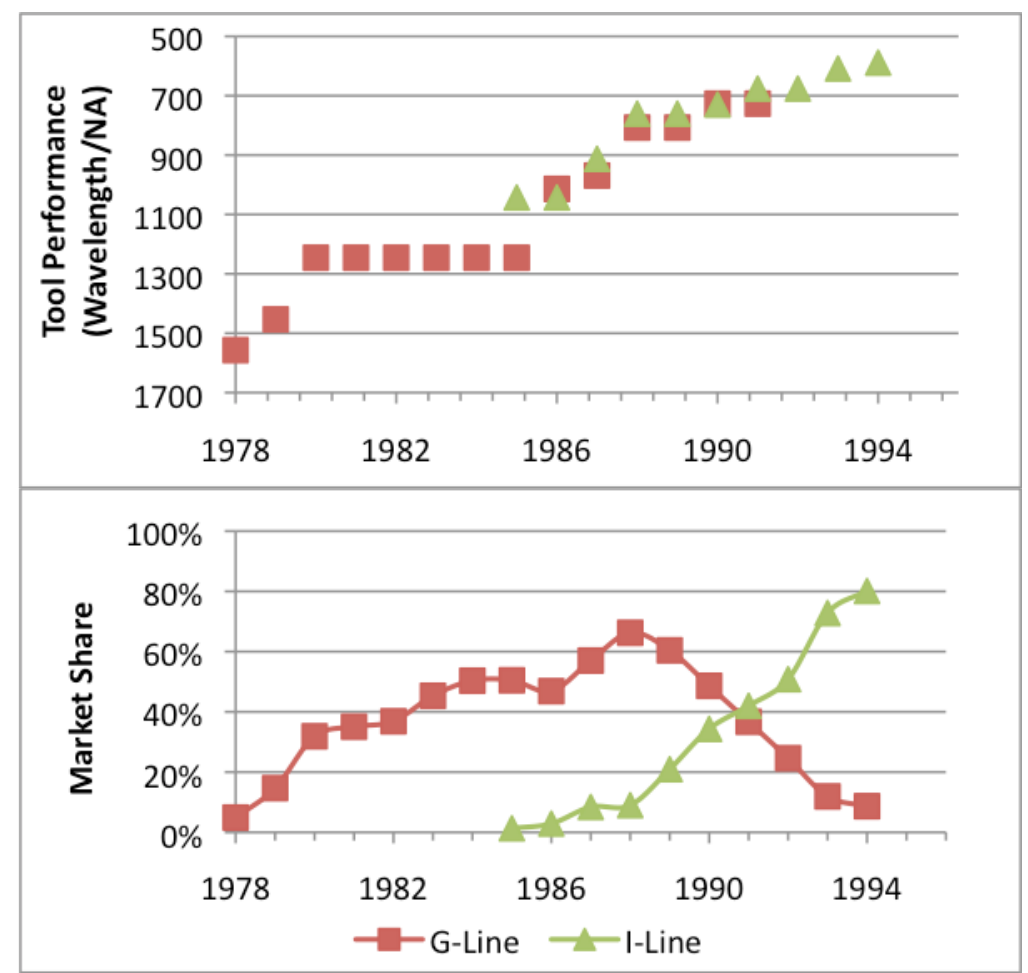

*The increase in market share for G-Line in the years 1987 and 1988 was due to the fact that G-Line was competing not only with I-Line at the higher end of the market, but also with Projection at the lower end of the market. The gains in G-Line's market share have a close correspondence with the decline in Projection's market share during this period. To make sure that our result is not affected by this somewhat artificial boost to G-line's market share, we ran a head-to-head market share analysis of G-line vs. I-line. To do this we looked only at G-line and I-line sales and excluded sales from all other generations. We then computed market shares in this two technology race and identified the year in which I-line's share exceeded G-line' share. The cross over year, 1991, remains as before. 
Figure 14: Difference in the pattern of substitution between Quadrant 1 (Proximity/Projection and DUV 193/DUV 193 immersion) and Quadrant 2 (G-Line/I-Line)

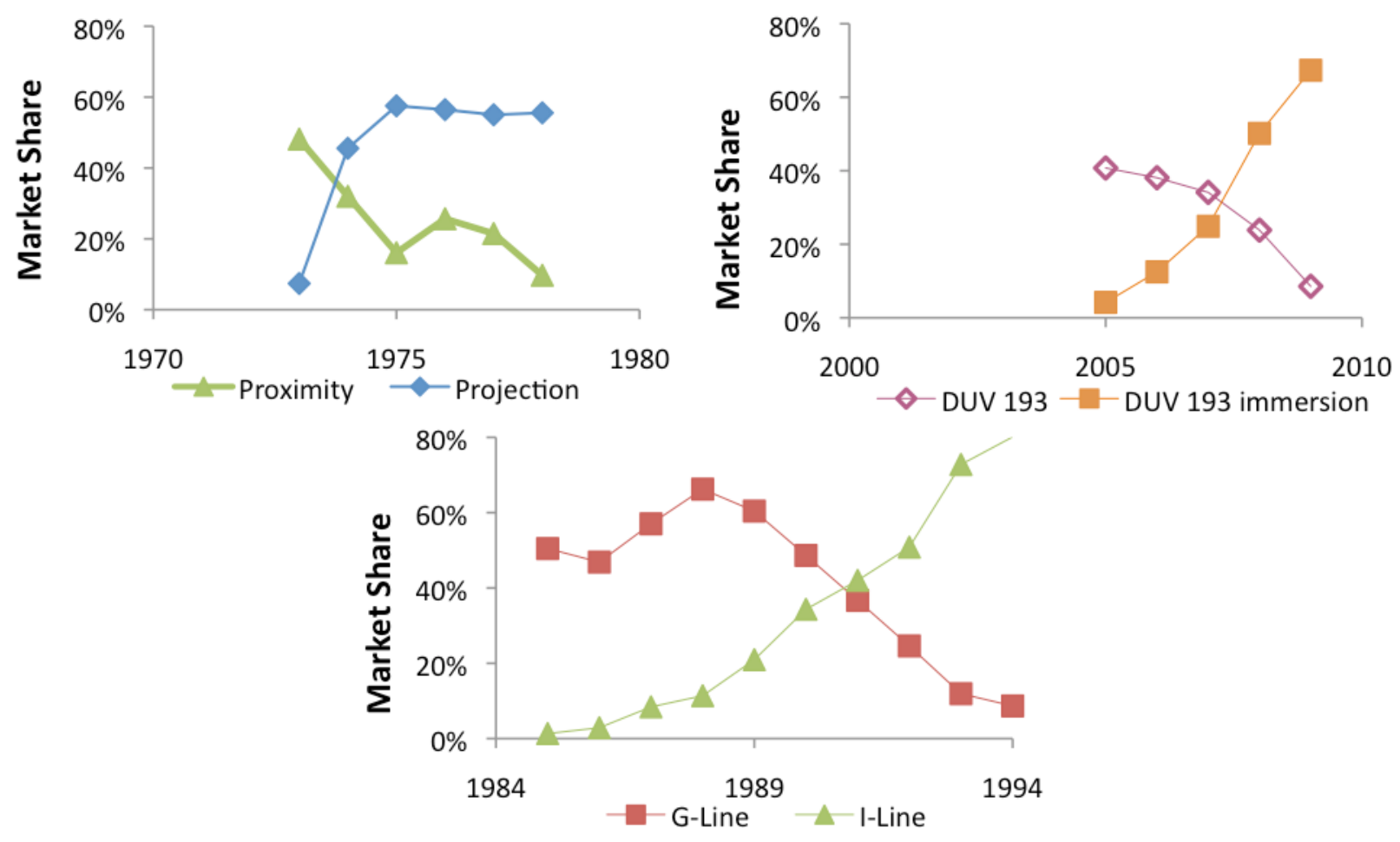

Figure 15: Demand for semiconductor equipment from the leading edge market segment

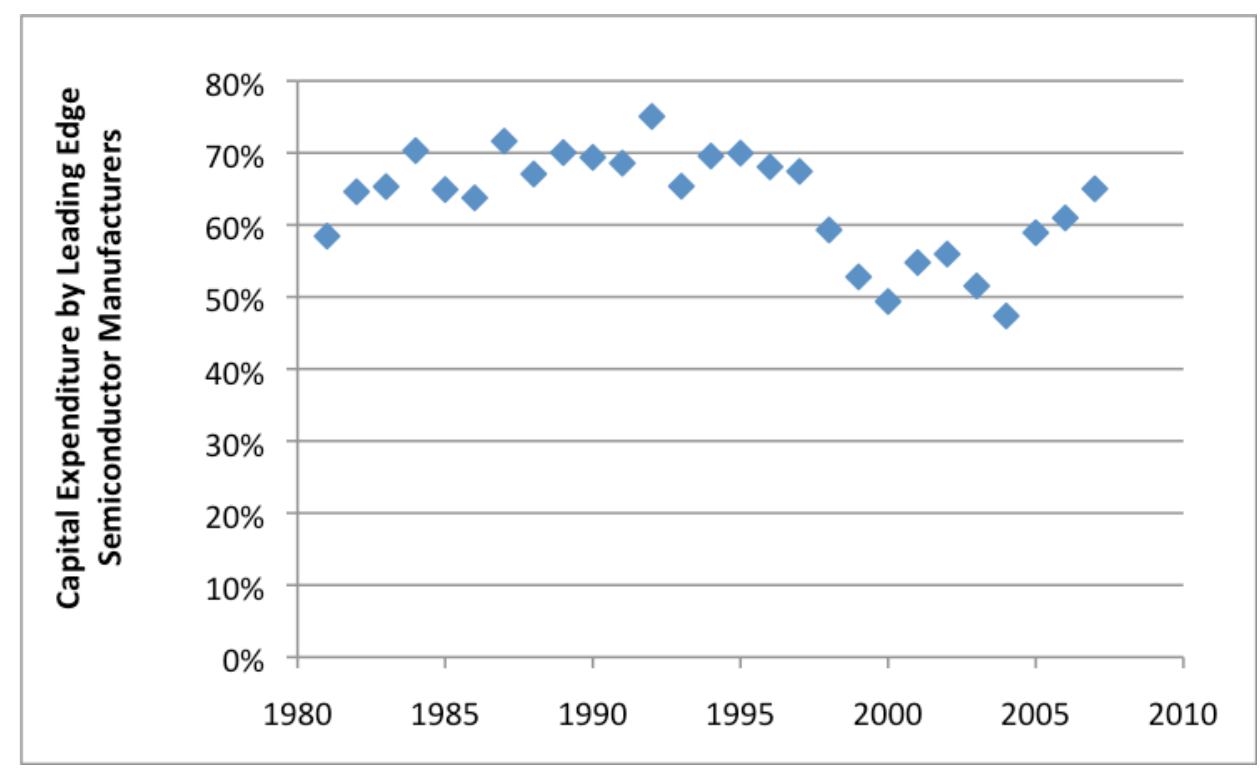




\section{Appendix I: Semiconductor Lithography Technology Generations}

Herewith, we describe each of the lithography technology generations and the major challenges that accompanied their development and commercialization.

\section{Contact Printers (First Generation)}

Contact printing was the earliest and the simplest of the lithography technologies to be commercialized in 1962. The modifier 'contact' corresponds to the fact that the mask and the semiconductor wafer were in direct contact with each other. The contact printers in the 1960's included a stage system for securing the mask and the wafer, and an alignment unit that ensured that the patterns from the mask were accurately transferred to the wafer. They used a mercury lamp for their light source, an existing component already used in movie projectors of the time. Contact printers did not incorporate a lens.

\section{Proximity Printers}

A primary disadvantage of contact printing was low process yield. This was due to the damage inflicted on the mask and the wafers as they were repeatedly brought in and out of physical contact with each other during the lithography process. Proximity printing, introduced in 1972, offered a way to overcome this problem. With proximity printing the mask and the wafer were separated by a tiny gap in order to reduce the defects that had been caused by their direct contact. This reconfiguration allowed for significant enhancement in the process yield during semiconductor manufacturing. As discussed in detail by Henderson and Clark (1990), this generational transition can be characterized as an architectural innovation and imposed significant innovation challenges on the focal lithography equipment firms. The transition to proximity printing did not, however, present major innovation challenges to any of the components and complements in the lithography ecosystem.

\section{Projection Scanners}

The continuous need of semiconductor manufacturers to reduce circuit dimensions and get better manufacturing yields led to the introduction of another architectural innovation in 1973. Projection scanners introduced the use of lens systems as a component in lithography tools. The lens system was composed of a series of reflective mirrors which allowed the image of the mask to be transferred to the wafer. The ecosystem challenges during the development and emergence of this generation were in the lens system, a new component that was developed specifically for the lithography industry; and in the mask, which needed to be etched with correspondingly smaller geometries and greater accuracy. To meet the mask manufacturing challenge, mask makers switched from using step and repeat cameras to using the more accurate electron beam systems in their production process.

\section{E-Beam Writers}

Electron-beam (E-beam) technology involves patterning the resist on the semiconductor wafer directly using electron beams the follow a pre-programmed pattern, thereby eliminating the need for a mask. A major concern with this approach has been its suitability for mass production. Since a preprogrammed electron beam travels across the wafer to achieve very low resolution, the time required to complete a single wafer can be as high as $10 \mathrm{hrs,} \mathrm{which} \mathrm{is} \mathrm{almost} \mathrm{an} \mathrm{order} \mathrm{of} \mathrm{magnitude} \mathrm{longer} \mathrm{than} \mathrm{the}$ alternate optical lithography technologies. The major component and complement challenges posed by Ebeam technology were the development of the E-beam source to increase throughput and the new resist chemistries that work with the emitted electrons.

\section{X-ray Printers}

The use of X-rays for lithography was proposed due to their very low wavelength of less than $10 \mathrm{~nm}$. In the early 1970 's, X-ray lithography was developed as a simple proximity imaging system. As 
in proximity printing, the radiation from an X-ray source is transmitted through the mask onto the resist. X-ray lithography's very low wavelength created substantial challenges to the development and implementation of the technology for semiconductor manufacturing. These challenges included major innovations required of the source and the mask.

\section{G-line}

Step-and-repeat (stepper) technology was introduced in 1978. The G-line stepper, an architectural innovation, introduced two key modifications. First, light was projected through the mask on to the wafer using a refractive lens system (as opposed to the reflective lens system used in projection scanners).

Second, the light was projected on only a part of the wafer at any one time; the mask was shifted across the wafer in steps, such that multiple exposures are made across the wafer to complete the lithography process. This significantly eased the challenge of mask making as the circuit patterns on the mask could now be $10 \mathrm{x}$ or $5 \mathrm{x}$ of the dimensions that need to be printed on to the wafer. Beyond challenges in the design of the tool, the transition to G-line steppers imposed challenges on the ecosystem. It required the development of a refractive lens comprised of several precise glass elements that would minimize distortion and transmit light accurately on to the wafer. It also required the development of a resist formulation that would allow for sufficiently small geometries; that is, a resist in which exposure to light energy would trigger a chemical reaction only in the molecules that were directly exposed to the light, without setting off a reaction in adjacent molecules. The resist challenge was resolved through the development of new novolac-based materials which replaced the negative resists which had been used to this point.

\section{I-line}

I-line steppers, introduced in 1985, used light with a wavelength of $365 \mathrm{~nm}$ to improve over the resolution achievable with the G-line generation. The main ecosystem challenge was to develop a lens that would transmit light at the lower wavelength. This required the development of a new glass material and corresponding changes to the lens production process. The remaining ecosystem elements required only incremental changes for the transition from the G-line generation.

\section{DUV 248}

The next step in the industry's technology evolution was the introduction of DUV 248nm steppers in 1988. This generation entailed a further reduction in wavelength into the deep ultraviolet (DUV) spectrum at $248 \mathrm{~nm}$. The reduction in wavelength required fundamental changes in the light source, the lens, the mask, and the resist. Mercury lamps, which had been used in all earlier generations, were not able to provide sufficient energy at a wavelength of $248 \mathrm{~nm}$ to cause adequate chemical reactions in the resist. This challenge was overcome by the development of excimer lasers using Krypton Fluoride (KrF) gas. The conventional glass material that was used to make lenses faced absorption problems with $248 \mathrm{~nm}$ wavelength. The only material that could be used was fused silica, and this required major changes to the lens manufacturing process. The challenges imposed on mask makers were overcome by changing the mask material from soda lime glass to quartz in order to provide improved transmission of the $248 \mathrm{~nm}$ wavelength. This, in turn, required major changes to the mask manufacturing process. Finally, the existing novolac resists could not absorb enough energy from the new wavelength to cause an adequate chemical reaction. As a result, new chemically-amplified resist had to be developed for semiconductor manufacturers to create fine circuits using the new lithography technology.

\section{DUV 193}

The industry's drive towards finer resolutions continued when tools using the 193nm wavelength were introduced in 1996. As was the case for the DUV 248nm technology, the very low light wavelength created new challenges in the ecosystem. Since KrF lasers could not produce light with wavelength of $193 \mathrm{~nm}$, a new excimer laser that used Argon Fluoride (ArF) gas was developed. New challenges were also posed by light absorption problems with the existing lens materials. These were overcome with the 
development of a new lens material, calcium fluoride $\left(\mathrm{CaF}_{2}\right)$. The resist also had to undergo major developments so that this new generation could create value for users. With the change to the $193 \mathrm{~nm}$ wavelength, the existing resists, which were engineered to react to the $248 \mathrm{~nm}$ wavelength, were no longer adequate to the task - a new generation of chemically amplified resist needed to be developed.

\section{DUV 157}

The subsequent attempts to achieve greater miniaturization resulted in the development of tools using the $157 \mathrm{~nm}$ wavelength. This required the development of a new excimer laser that used Fluorine $\left(\mathrm{F}_{2}\right)$. The reduction in wavelength created transmittance problems with the existing lenses. To overcome this problem, lenses required much higher concentrations of $\mathrm{CaF}_{2}$ than ever before, which created enormous challenges in the lens manufacturing process. DUV $157 \mathrm{~nm}$ technology also required that the mask substrate and the pellicle materials to be completely redeveloped to effectively transmit the low wavelength light.

\section{DUV 193-immersion}

The most recent transition in 2005 has been the introduction of the 193 immersion generation. This transition was enabled by an architectural innovation in which liquid (instead of air) is used as a medium between the lens and the wafer. The generation required major efforts by tool producers to manage the flow of liquid in this complex architecture. The transition did not, however, present major innovation challenges to any other elements in the lithography ecosystem. As the wavelength of light did not change, the new generation was able to reuse all the existing ecosystem elements of source, lens, resist and mask with relatively minor improvements. 
Appendix II: Pace of substitution in the semiconductor lithography industry organized within our framework according to the extension opportunity for every mainstream old technology and the emergence challenge for the new technology. Years for the new technology to achieve higher market share than the old technology are in parentheses. ${ }^{a}$

\begin{tabular}{|c|c|c|}
\hline & $\begin{array}{c}\text { Ecosystem Extension Oppor } \\
\text { Low }\end{array}$ & $\begin{array}{c}\text { y for Old Technology } \\
\text { High }\end{array}$ \\
\hline 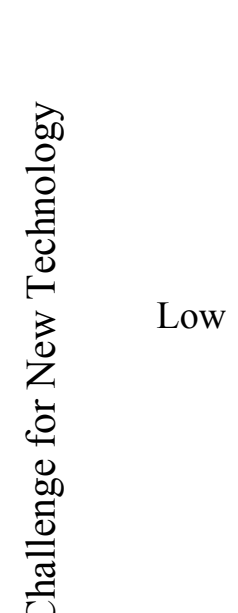 & $\begin{array}{l}\text { Quadrant 1: Creative Destruction } \\
\text { Contact } \rightarrow \text { Proximity (2) } \\
\text { Proximity } \rightarrow \text { Projection (2) } \\
\text { Projection } \rightarrow \text { G-line (5) } \\
\text { DUV } 193 \rightarrow \text { DUV 193i (4) } \\
\text { Contact } \rightarrow \text { Projection (2) } \\
\text { Proximity } \rightarrow \text { G-line (2) } \\
\text { Projection } \rightarrow \text { I-Line (4) } \\
\text { I-Line } \rightarrow \text { DUV 193i (2) } \\
\text { DUV 248 } \rightarrow \text { DUV 193i (3) }\end{array}$ & $\begin{array}{l}\text { Quadrant 2: Robust Coexistence } \\
\text { G-line } \rightarrow \text { I-line (7) }\end{array}$ \\
\hline 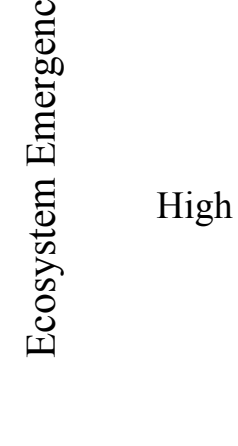 & $\begin{array}{l}\text { Quadrant 3: Resilience Illusion } \\
\text { Projection } \rightarrow \text { E-beam }(--)^{\mathrm{b}} \\
\text { Projection } \rightarrow \text { X-ray }(--)^{\mathrm{b}} \\
\text { G-line } \rightarrow \text { DUV } 248(8) \\
\text { Projection } \rightarrow \text { DUV } 248(5) \\
\text { I-line } \rightarrow \text { DUV } 193(7) \\
\text { I-Line } \rightarrow \text { DUV } 157(--)^{\mathrm{b}}\end{array}$ & $\begin{array}{l}\text { Quadrant 4: Robust Resilience } \\
\text { I-line } \rightarrow \text { DUV 248(11) } \\
\text { DUV } 248 \rightarrow \text { DUV } 193(11) \\
\text { DUV } 193 \rightarrow \text { DUV } 157(--)^{c} \\
\text { DUV } 248 \rightarrow \text { DUV } 157(--)^{c}\end{array}$ \\
\hline
\end{tabular}

${ }^{a}$ Pace of substitution is defined as the number of years required for the new technology to overtake the market share of every prior technology that had achieved dominant market share and still held at least ten percent share when the new technology was introduced (the ten percent boundary assures that the old technology was still contending for mainstream customers; i.e., it precludes comparisons such as projection vs. 193i. Competitive pairs are Old Technology $\rightarrow$ New Technology.

${ }^{\mathrm{b}}$ The introduction of E-beam was followed by X-ray which was itself followed by the introduction of G-line and hence, the technology competition rapidly shifted from the mode of old vs. new technology to old vs. newer technology. Although neither E-beam nor X-ray ever displaced Projection (indeed the emergence challenges with both were so great that neither has been able to take off for the last three decades), the 'illusion' of Projection's resilience was demonstrated by how quickly Projection was displaced by G-line. The same pattern also applies to competition between I-Line and DUV 157 i.e. it was rapidly substituted by DUV 193i as shown in Quadrant 1.

${ }^{c}$ The ecosystem emergence challenges with DUV 157 were so great that it did not ever achieve dominance over the old technology. 


\section{Appendix III: Hedonic Regression Analysis of Lithography Tool Price. ${ }^{\text {a }}$}

\begin{tabular}{|l|l|l|}
\hline & \multicolumn{2}{|c|}{$\begin{array}{c}\text { Dependent Variable }= \\
\text { Lnflated price in 2004\$) }\end{array}$} \\
\hline & Model 1 & Model 2 \\
\hline Ln(Resolution in nm) & $-1.162^{* * *}$ & $-0.917 * * *$ \\
\hline & $(0.045)$ & $(0.121)$ \\
\hline DUV 193 & & $1.378^{* * *}$ \\
\hline & & $(0.398)$ \\
\hline DUV 248 & & $1.398 * *$ \\
\hline & & $(0.310)$ \\
\hline I-Line & & $1.267 * * *$ \\
\hline & & $(0.237)$ \\
\hline G-Line & & $1.076 * * *$ \\
\hline & & $(0.184)$ \\
\hline Projection & & $1.135 * * *$ \\
\hline & & $(0.176)$ \\
\hline Constant & $22.058^{* * *}$ & $19.348 * * *$ \\
\hline & $(0.286)$ & $(0.945)$ \\
\hline Observations & 90 & 90 \\
\hline Adjusted R-squared & 0.88 & 0.92 \\
\hline & & \\
\hline
\end{tabular}

Proximity is the omitted technology category

Standard errors in parentheses

* significant at $10 \%$;* significant at $5 \%$; ** significant at $1 \%$.

${ }^{a}$ The data for the hedonic analysis was collected from tool manufacturer's product brochures and from VLSI Research. 